\title{
Adjuvanted poly(lactic-co-glycolic) acid nanoparticle-entrapped inactivated porcine reproductive and respiratory syndrome virus vaccine elicits cross-protective immune response in pigs
}

This article was published in the following Dove Press journal:

International Journal of Nanomedicine

24 January 2014

Number of times this article has been viewed

\author{
Basavaraj Binjawadagi ${ }^{1,2}$ \\ Varun Dwivedi' \\ Cordelia Manickam ${ }^{1,2}$ \\ Kang Ouyang' \\ Yun $\mathrm{Wu}^{3}$ \\ Ly James Lee ${ }^{3}$ \\ Jordi B Torrelles ${ }^{4}$ \\ Gourapura J \\ Renukaradhya ${ }^{1,2}$ \\ 'Food Animal Health Research \\ Program, Ohio Agricultural \\ Research and Development Center, \\ ${ }^{2}$ Department of Veterinary Preventive \\ Medicine, Ohio State University, \\ Wooster, OH, USA; ${ }^{3}$ NanoScale \\ Science and Engineering Center \\ for Affordable Nanoengineering \\ of Polymeric Biomedical Devices, \\ ${ }^{4}$ Department of Microbial Infection \\ and Immunity, Ohio State University, \\ Columbus, $\mathrm{OH}, \mathrm{USA}$
}

\begin{abstract}
Porcine reproductive and respiratory syndrome (PRRS), caused by the PRRS virus (PRRSV), is an economically devastating disease, causing daily losses of approximately $\$ 3$ million to the US pork industry. Current vaccines have failed to completely prevent PRRS outbreaks. Recently, we have shown that poly(lactic-co-glycolic) acid (PLGA) nanoparticleentrapped inactivated PRRSV vaccine (NP-KAg) induces a cross-protective immune response in pigs. To further improve its cross-protective efficacy, the NP-KAg vaccine formulation was slightly modified, and pigs were coadministered the vaccine twice intranasally with a potent adjuvant: Mycobacterium tuberculosis whole-cell lysate. In vaccinated virulent heterologous PRRSV-challenged pigs, the immune correlates in the blood were as follows: 1) enhanced PRRSV-specific antibody response with enhanced avidity of both immunoglobulin (Ig)-G and IgA isotypes, associated with augmented virus-neutralizing antibody titers; 2) comparable and increased levels of virus-specific $\mathrm{IgG}_{1}$ and $\mathrm{IgG}_{2}$ antibody subtypes and production of high levels of both T-helper (Th)-1 and Th2 cytokines, indicative of a balanced Th1-Th2 response; 3) suppressed immunosuppressive cytokine response; 4) increased frequency of interferon- $\gamma^{+}$ lymphocyte subsets and expanded population of antigen-presenting cells; and most importantly 5) complete clearance of detectable replicating challenged heterologous PRRSV and close to threefold reduction in viral ribonucleic acid load detected in the blood. In conclusion, intranasal delivery of adjuvanted NP-KAg vaccine formulation to growing pigs elicited a broadly crossprotective immune response, showing the potential of this innovative vaccination strategy to prevent PRRS outbreaks in pigs. A similar approach to control other respiratory diseases in food animals and humans appears to be feasible.
\end{abstract}

Keywords: porcine reproductive and respiratory syndrome, mucosal vaccine, nanoparticles, cross-protection, pigs

\section{Introduction}

Porcine reproductive and respiratory syndrome (PRRS) is responsible for greater than $\$ 664$ million direct loss to the US pork industry annually. ${ }^{1}$ The causative agent, PRRS virus (PRRSV), is an enveloped positive-sense ribonucleic acid (RNA) virus that belongs to the family Arteriviridae. There are two known PRRSV genotypes, European (type I) and North American (type II), with varying inter- and intragenotypic, genetic, and antigenic diversity signifying the high mutagenic nature of the virus. ${ }^{2}$
Renukaradhya

Food Animal Health Research Program,

Ohio Agricultural Research and Development Center, Ohio State University, 1680 Madison Avenue,

Wooster, OH 4469I, USA

$\mathrm{Tel}+\mathrm{I} 3302633748$

Fax +I 3302633677

Email gourapura.I@osu.edu 
Since the 1990s, both modified live (PRRS-MLV) and inactivated PRRSV vaccines have been in use, but control of PRRS has remained unsuccessful. Moreover, PRRS-MLV has been implicated in the spread of mutated vaccine virus to susceptible pigs. ${ }^{3}$ Available inactivated vaccines are safe, but poorly immunogenic. ${ }^{4}$ Therefore, the development of a potent inactivated PRRSV vaccine is warranted.

There are limitations associated with current PRRSVkilled vaccines, such as the antigens are soluble in nature, poorly immunogenic, viral proteins degrade by proteolytic enzymes, insufficient antigenic mass in vaccine formulations, etc. Since PRRSV enters its host primarily through respiratory and genital mucosal surfaces, delivery of PRRSV vaccine by the noninvasive intranasal route to induce robust local mucosal immunity appears to be beneficial. Moreover, the primary target cells of PRRSV are alveolar and interstitial macrophages, and the virus causes disease primarily in the lungs. ${ }^{5,6}$ Intranasal immunization is not only efficient in stimulating protective immune responses in the lungs but also elicits immune responses at distant sites, such as gastric and genital mucosa. ${ }^{7}$

Ultraviolet (UV) or chemical (eg, binary ethylenimine) inactivation of PRRSV preserves immunogenic epitopes. ${ }^{8}$ UV- or binary ethylenimine-inactivated PRRSV has several advantages over PRRS-MLV: unlike the live PRRSV, inactivated virus does not downregulate secretion of the important innate cytokine interferon (IFN)- $\alpha$; such an inactivation procedure preserves the viral neutralizing epitopes; and abrogation of development of regulatory T-cell subsets..$^{8-11}$ However, the delivery of inactivated virus alone in a vaccine formulation is not efficacious, and it needs coupling with a potent adjuvant/s. ${ }^{12}$ We have previously established adjuvant effects of $\mathrm{Myco-}$ bacterium tuberculosis ([M. tb] whole-cell lysate [WCL]) to PRRS-MLV. ${ }^{13-15} M . t b$ WCL is an endotoxin-free extract containing only water-soluble components of the bacterium, shown to possess potent adjuvant effects in rodents, guinea pigs, and rabbits. ${ }^{16,17}$ Importantly, unlike complete Freund's adjuvant, $M$. $t b \mathrm{WCL}$ is free from water-insoluble toxic cellwall components of the bacterium. ${ }^{18,19}$ Therefore, $M$. $t b$ WCL does not cause any toxicity or granulomatous inflammatory reaction at the site of injection or inoculation. ${ }^{17}$ Components M. $t b \mathrm{WCL}$, such as heat shock protein 70 and PE (ProGlu)/PPE (Pro-Pro-Glu) have been shown to possess potent adjuvant activity, driving primarily T-helper (Th)-1-biased responses. ${ }^{20,21}$ Biodegradable, biocompatible, nontoxic, repetitive polymers, such as poly(lactic-co-glycolic) acid (PLGA)based micro/nanoparticles (NPs), are being used widely for targeted drug and vaccine delivery. ${ }^{22}$ Moreover, PLGA is a
US Food and Drug Administration- and European Medicines Agency-approved polymer for various human applications. Soluble vaccine antigens entrapped in PLGA NPs of up to $5 \mu \mathrm{m}$ in size have been shown to protect encased antigen/drug from enzymatic or ionic degradation in vivo. ${ }^{23,24}$ Immunization with NP (200-600 nm size range) vaccines enhances IFN $\gamma$ production, long-lasting antigen-specific T-cell response, and production of high-affinity neutralizing antibodies. ${ }^{25-28}$

Intranasally delivered particulate antigens are sampled readily by mucosal M-cells of the nasal lymphoid tissues and delivered to underlying professional antigen-presenting cells (APCs) in the respiratory tract. ${ }^{29}$ Recently, we have shown that a single-dose of PLGA NP-entrapped inactivated PRRSV (NP-KAg) vaccine delivered intranasally to pigs elicits antiPRRSV immune responses. ${ }^{30,31}$ In order to reinforce further the efficacy of NP-KAg vaccine, we slightly modified the vaccine constituents and coadministered the vaccine with the potent adjuvant $M$. $t b$ WCL twice intranasally. In vaccinated pigs, enhanced cross-protective humoral and cell-mediated immune responses against a challenged PRRSV were detected, which were associated with the complete clearance of detectable replicating challenged heterologous virus (not the viral RNA) in the blood.

\section{Materials and methods Reagents}

MARC 145 cells $^{32}$ were used to prepare PRRSV stocks and assays. Cells were maintained in Dulbecco's Modified Eagle's Medium (DMEM) containing 10\% fetal bovine serum. For virus infection, DMEM with $2 \%$ horse serum was used. North American prototype PRRSV strain VR $2332^{2}$ was used in vaccine preparation (provided by Dr Eric Nelson, South Dakota State University, USA), and PRRSV MN $184^{2}$ was provided by Dr Michael Murtaugh (University of Minnesota, USA). M. $t b \mathrm{WCL}$ was prepared as previously described..$^{33}$

\section{Preparation of vaccine antigens and PLGA nanoparticle-based vaccine formulations}

PRRSV strain VR $2332^{2}$ was grown and UV-killed/inactivated (KAg) as described previously. ${ }^{13,30}$ PLGA NPs entrapping KAg (NP-KAg) or $M$. $t b$ WCL (NP-M. $t b$ WCL) were prepared using a double-emulsion method $(\mathrm{w} / \mathrm{o} / \mathrm{w})$ as previously described, ${ }^{34}$ with a few modifications. ${ }^{26}$ Briefly, 4\% PLGA (75:25) polymer solution (molecular weight 66,000-107,000; Sigma-Aldrich, St Louis, MO, USA) was prepared by dissolving $0.18 \mathrm{~g}$ PLGA in $4.5 \mathrm{~mL}$ of dichloromethane. PRRSV Ags or $M$. $t b$ WCL $(5 \mathrm{mg})$ in $0.5 \mathrm{~mL}$ 
phosphate-buffered saline (PBS) was mixed in $0.25 \mathrm{~mL}$ of $2 \%$ polyvinyl alcohol (molecular weight 85,000-124,000; Sigma-Aldrich) prepared in $10 \mathrm{mM}$ 4-(2-hydroxyethyl)-1piperazineethanesulfonic acid buffer ( $\mathrm{pH} 7.5)$, and sucrose and magnesium hydroxide (each $0.25 \mathrm{~mL}$ at $2 \%$ ) were added to the PLGA polymer solution and probe-sonicated for 30 seconds (Branson Sonifier ${ }^{\circledR} 450$; Emerson Industrial Automation, Danbury, CT, USA) with a duty cycle of $30 \%$ and output control of three. The resulting water-in-oil (w/o) emulsion was divided into two tubes, and $11.5 \mathrm{~mL}$ of $2 \%$ polyvinyl alcohol and $1 \mathrm{~mL}$ of $12.5 \%$ poloxamer 188 solution were added to each tube and sonicated again for 60 seconds to obtain the final w/o/w emulsion. Contents of both the tubes were pooled and stirred for 20 hours with a magnetic stirrer at $400 \mathrm{rpm}$ at $4{ }^{\circ} \mathrm{C}$ to evaporate the solvent. Tubes were then centrifuged at 10,976 $\times g($ FX6100 router; Beckman Coulter, Pasadena, CA, USA), and the pellet containing the NPs was washed in sterile distilled water for 30 minutes three times. Finally, NPs were suspended in $5 \mathrm{~mL}$ of $5 \%$ sucrose solution and freeze-dried for 18-20 hours, and the lyophilized powder was stored at $-20^{\circ} \mathrm{C}$.

\section{Determination of protein-entrapment efficiency and characterization of NP-KAg}

Protein entrapped in NPs was estimated as described previously. ${ }^{13,30}$ Morphology of the NP-KAg was visualized using a Philips (Amsterdam, the Netherlands) XL30-FEG scanning electron microscope at $20 \mathrm{kV}$ with $30,000 \times$ magnification. Size distribution of the sham- or KAg-entrapped NPs was measured using a Nicomp 370 particle sizer (Particle Sizing Systems, Port Richey, FL, USA). The zeta potential of the NPs was determined by ZetaPALS (Brookhaven Instruments, Holtsville, NY, USA).

\section{Determination of in vitro protein release from NP-KAg vaccine}

The protein-release profile from NP-KAg vaccine was determined as previously described. ${ }^{35}$ Briefly, $50 \mathrm{mg}$ NPKAg was suspended in $1 \mathrm{~mL}$ sterile PBS and centrifuged at $11,400 \times g$ for 10 minutes at $4^{\circ} \mathrm{C}$, and the supernatant was collected to estimate the burst release. The pellet containing NP-KAg was resuspended in $1 \mathrm{~mL}$ PBS, and the harvested supernatants were collected at 1, 5, 10, 15, 20, 25, and 30 days and stored at $-20^{\circ} \mathrm{C}$. On day 30 , the remaining NP-KAg was lysed using lysis buffer to recover the protein, and the protein concentration of all the samples was estimated by bicinchoninic acid assay. ${ }^{30}$

\section{In vitro uptake of NP-KAg by PAM cells}

NP-KAg vaccine containing $2 \mu \mathrm{g}$ of PRRSV KAg was suspended in $1 \mathrm{~mL}$ of Roswell Park Memorial Institute medium and incubated with porcine alveolar macrophage (PAM) cells (3D4/2; American Type Culture Collection, Manassas, VA, USA) for 0, 5, 20, and 30 minutes, and 3, 12, and 24 hours. As controls, KAg ( $2 \mu \mathrm{g})$ and sham NP-treated PAM cells and MARC 145 cells (as PRRSV cannot infect 3D4/2 cells) were infected for 24 hours with PRRSV strain VR2332. Cells were washed and fixed with $80 \%$ acetone and incubated with PRRSV $\mathrm{N}^{\prime}$ monoclonal antibody (mAb) SDOW17 (Rural Technologies, Brookings, SD, USA), followed by antimouse immunoglobulin (Ig)-G (H+L) Alexa 488 (Life Technologies, Carlsbad, CA, USA) and observed under fluorescent microscope.

\section{Pigs and inoculations}

Conventional large white Duroc crossbred, specific pathogen-free weaned (3-4 weeks) piglets were procured from a swineherd seronegative for PRRSV, porcine respiratory coronavirus, transmissible gastroenteritis virus, and porcine circovirus 2 antibodies. A total of 30 pigs were randomly divided into one of the ten groups (three pigs/group) and vaccinated with the indicated vaccine adjuvant formulation (Table 1). Every dose of PRRSV vaccine had either 100 (low) or 500 (high) $\mathrm{mg}$ of semipurified viral protein equivalent to approximately $0.5 \times 10^{6}$ or $2.5 \times 10^{6} 50 \%$ tissue-culture infective dose $\left(\mathrm{TCID}_{50}\right)$ of killed PRRSV, respectively, and adjuvant $M . t b$ WCL (1 mg/dose/pig). The vaccine and adjuvant, either encapsulated in NPs or unencapsulated, were inoculated intranasally twice at 2-week intervals ( $2 \mathrm{~mL} / \mathrm{pig}$ ) (Table 1 ). Except pigs in group 1, all the other groups were challenged on postvaccination day 28 with the virulent heterologous North American PRRSV (type II) strain MN184 $\left(5 \times 10^{5}\right.$ $\mathrm{TCID}_{50} / \mathrm{pig}$ ), which is genetically highly divergent (only $85 \%$ identical) to the vaccine strain VR2332. ${ }^{2}$ Adjuvant and vaccine were entrapped separately and combined before immunization. The doses of the adjuvant and NP-KAg had been tested to be efficacious earlier. ${ }^{15,30,34}$ Pigs were killed at postchallenge (PC) day 15. Pigs were monitored daily for respiratory disease, and rectal temperatures and body weights were recorded every third day postchallenge. Animals were maintained with food and water ad libitum, and samples collected and pigs killed as per the approved protocol of the Institutional Animal Care and Use Committee of the Ohio State University.

\section{Analysis of PRRSV-specific antibodies}

Heparinized blood samples (3-5 mL) were collected on both the days of vaccination, and at PC day $0,6,10$, and 15 , and 
Table I Grouping of vaccine trial pigs

\begin{tabular}{|c|c|c|}
\hline Groups & \multicolumn{2}{|l|}{ Vaccine trial pig groups } \\
\hline I & \multicolumn{2}{|l|}{ Mock pigs (PBS and DMEM) } \\
\hline \multirow[t]{3}{*}{2} & \multicolumn{2}{|c|}{ Mock + challenged (Chal) with PRRSV- MNI 84 strain } \\
\hline & Vaccine dose & Vaccine dose \\
\hline & (100 $\mu$ g/pig) + Chal & $(500 \mu g /$ pig $)+$ Chal \\
\hline 3 & $100 \mu \mathrm{g}$ of $\mathrm{KAg}$ & 3. $500 \mu \mathrm{g}$ of $\mathrm{KAg}$ \\
\hline \multirow[t]{2}{*}{4} & $100 \mu g$ of & 4. $500 \mu \mathrm{g}$ of \\
\hline & $\mathrm{KAg}+M . t b \mathrm{WCL}$ & $\mathrm{KAg}+M . t b \mathrm{WCL}$ \\
\hline \multirow[t]{2}{*}{5} & $100 \mu g$ of & 5. $500 \mu g$ of \\
\hline & NP-KAg + NP-M. tb WCL & $N P-K A g+N P-M . t b$ WCL \\
\hline \multirow[t]{2}{*}{6} & $100 \mu g$ of & 6. $500 \mu g$ of \\
\hline & $\mathrm{NP}-\mathrm{KAg}+\mathrm{M} . t b \mathrm{WCL}$ & $\mathrm{NP}-\mathrm{KAg}+\mathrm{M} . t b \mathrm{WCL}$ \\
\hline
\end{tabular}

Notes: $A$ total of 30 pigs were divided into ten groups ( $n=3$ pigs per group). Groups $\mathrm{I}$ and 2 served as mock and mock vaccinated-challenged, respectively. The other eight pig groups were divided into two vaccine-dose categories (100 or $500 \mu \mathrm{g} / \mathrm{pig}$ ), as detailed above. For statistical comparison, groups I and 2 were considered with both the vaccine-dose categories.

Abbreviations: PBS, phosphate-buffered saline; DMEM, Dulbecco's Modified Eagle's Medium; PRRSV, porcine reproductive and respiratory syndrome virus; $\mathrm{KAg}$, killed antigen; Chal, challenge; M. tb WCL, whole-cell lysate of Mycobacterium tuberculosis; NP, nanoparticle; NP-KAg, nanoparticle-entrapped inactivated PRRSV vaccine.

separated plasma was aliquoted and preserved at $-70^{\circ} \mathrm{C}$. PRRSV-specific antibody responses were determined as described previously. ${ }^{36}$ Briefly, enzyme-linked immunosorbent assay (ELISA) plates were coated with pretitrated semipurified MN184 Ags ( $5 \mu \mathrm{g} / \mathrm{mL})$ or with PRRSV-recombinant $\mathrm{N}, \mathrm{M}$, or GP5 proteins $(5 \mu \mathrm{g} / \mathrm{mL})$. A mean optical density (OD) value of 30 tenfold-diluted PRRSV-negative plasma samples plus twice the standard deviation was considered the positive-negative cutoff. The reciprocal of the highest dilution of the plasma sample that showed an OD value above the cutoff OD was considered the end titer. PRRSV-specific $\operatorname{IgG}_{1}$ and $\mathrm{IgG}_{2}$ antibodies in the plasma samples were analyzed as described previously. ${ }^{37}$

\section{Avidity of PRRSV-specific antibodies in the lungs and blood}

PRRSV-specific antibody avidity was determined as described previously, ${ }^{38}$ with a few modifications. Briefly, the plasma samples (1:100) were added to PRRSV Ags-coated ELISA plates and incubated. Plates were washed four times, serially twofold diluted in $\mathrm{NH}_{4} \mathrm{CN}(5-0.313 \mathrm{M})$, and incubated for 10 minutes at room temperature. The remaining procedure was followed as described earlier to estimate PRRSV-specific antibodies. The OD value of the test sample from $\mathrm{NH}_{4} \mathrm{CN}$-untreated $(0 \mathrm{M})$ wells was considered $100 \%$ absorbance. The test-sample OD value from $\mathrm{NH}_{4} \mathrm{CN}$-treated wells was compared to untreated $(0 \mathrm{M})$ wells of the corresponding sample to estimate the retained $\mathrm{Ag}-\mathrm{Ab}$ complex, which is expressed as percentage absorbance.

\section{Estimation of PRRSV-specific IgG, and $\lg G_{2}$ antibodies}

To determine Th1- and Th2-biased PRRSV-specific antibody responses, the levels of virus-specific $\mathrm{IgG}_{1}$ and $\mathrm{IgG}_{2}$ antibodies in the plasma samples were analyzed as described previously, ${ }^{37}$ with a few modifications. Briefly, killed semipurified PRRSV (MN184) Ags $(5 \mu \mathrm{g} / \mathrm{mL})$-coated plates were blocked and plated with a serial tenfold dilution of plasma samples, and the plate-bound virus-specific $\operatorname{IgG}_{1}$ and $\mathrm{IgG}_{2}$ were detected using mouse antipig $\operatorname{IgG}_{1}$ and $\mathrm{IgG}_{2}$ (AbD Serotec; Bio-Rad Laboratories, Hercules, CA, USA) (1:250 dilution), respectively. Subsequently, the designated wells were treated with goat antimouse horseradish peroxidase (Sigma-Aldrich) (1:10,000 dilution).$^{39}$ The reaction was developed using $3,3^{\prime}, 5,5^{\prime}$-tetramethylbenzidine substrate and stopped using $1 \mathrm{M}$ phosphoric acid and read at $\mathrm{OD}_{450}$. For calculation of the PRRSV-specific $\operatorname{IgG}_{1}$ and $\operatorname{IgG}_{2}$ antibody levels of test samples, the OD values at 1:500 dilution were considered.

\section{Estimation of different cytokines by ELISA}

For analysis of recall cytokine response, $4 \times 10^{6}$ peripheral blood mononuclear cells (PBMCs) were stimulated with semipurified killed PRRSV (MN184) Ags (50 $\mu \mathrm{g} / \mathrm{mL}$ ). Cells unstimulated and stimulated with Phytohemagglutinin (Sigma-Aldrich) $(10 \mu \mathrm{g} / \mathrm{mL})$ served as controls. The culture supernatant was harvested after 48 hours and analyzed for proinflammatory (interleukin [IL]-6), immunosuppressive (IL-10), and Th2 (IL-4) cytokines by ELISA, as described previously. ${ }^{14}$

\section{Flow cytometry analyses}

The phenotypes and frequencies of lymphoid and myeloid cell populations from 50,000 events of immunostained PBMCs were determined by flow cytometry, as described previously. ${ }^{31}$ For intracellular IFN $\gamma$ staining, GolgiPlug ${ }^{\mathrm{TM}}$ (BD Biosciences, San Jose, CA, USA) was added during the last 6 hours of incubation of PBMCs that were unstimulated or stimulated with PRRSV Ags, as described above. PBMCs were first surface-labeled using pig lymphocytespecific mAbs (CD3e, CD4a, CD8a, CD56, and TcR1N4) directly conjugated with different fluorochromes. Cells were fixed with $1 \%$ paraformaldehyde and permeabilized with a cell-permeabilization buffer $(85.9 \%$ deionized water, $11 \%$ PBS with no $\mathrm{Ca}$ or $\mathrm{Mg}, 3 \%$ formaldehyde solution, and $0.1 \%$ saponin) overnight at $4^{\circ} \mathrm{C}$. Cells were washed and stained with fluorochrome-conjugated pig IFN $\gamma$ or its 
isotype control $\mathrm{mAb}$ (BD Biosciences) in $0.1 \%$ saponin containing fluorescence-activated cell-sorting (FACS) buffer. Immunostained cells were acquired using the FACS Aria II (BD Biosciences) flow cytometer and analyzed using Flow Jo (Tree Star, Ashland, OR, USA) software. All specific immune population frequencies were presented as the percentage of total lymphocytes or myeloid cells.

\section{Determination of PRRSV load, RNA copies, and virus-neutralization titers}

PRRSV titer and virus-neutralizing (VN) antibody titer in the plasma samples were analyzed by the indirect immunofluorescence assay. ${ }^{14,32}$ Briefly, for virus titration, a confluent monolayer of MARC 145 cells in 96-well microtiter plate was treated with tenfold dilution of plasma for 24 hours.

The PRRS viral titers in each milliliter of plasma and virus-specific VN titers were calculated. The PRRSV RNA copy numbers were detected in each milliliter of the plasma by qRT-PCR, as previously described. ${ }^{31}$ For VN assay, twofold serially diluted plasma samples were incubated with one of the PRRSV strains: MN184 (250 TCID 50 ), PRRSV 1-4-4 (accession \#10-16734) $)^{40}\left(100 \mathrm{TCID}_{50}\right)$, or SD03-15 $5^{41}$ $\left(200 \mathrm{TCID}_{50}\right)$.

\section{Statistical analysis}

Data are expressed as means \pm standard error of mean of three pigs. Statistical analyses were performed by one-way analysis of variance, followed by Tukey's $t$-test and unpaired $t$-test to compare certain results using Instat5 (GraphPad Software, La Jolla, CA, USA). Comparisons were performed between different treatment groups, and $P<0.05$ was considered statistically significant, as indicated by the letters $a-j$ mentioned below.

$\mathrm{a} \rightarrow$ group 2 versus group 3 ; b $\rightarrow$ group 2 versus group

4 ; c $\rightarrow$ group 2 versus group 5;

$\mathrm{d} \rightarrow$ group 2 versus group 6; e $\rightarrow$ group 3 versus group

$4 ; \mathrm{f} \rightarrow$ group 3 versus group 5 ;

$\mathrm{g} \rightarrow$ group 3 versus group $6 ; \mathrm{h} \rightarrow$ group 4 versus group

$5 ; \mathrm{i} \rightarrow$ group 4 versus group 6; and

$\mathrm{j} \rightarrow$ group 5 versus group 6 .

\section{Results}

\section{Physical and biological characterization of NP-KAg vaccine}

The potency of NP-mediated delivery of drugs or vaccines depends on their loading capacity and size. ${ }^{42}$ The entrapment efficiency of killed-PRRSV antigens (KAg) or $M$. $t b$ WCL in NPs was about 50\%-60\%. Both sham- and entrapped NPs were circular in shape (Figure 1A). Dynamic light scattering of NPs determined their diameter-based distribution, and the mean diameter \pm standard deviation of sham NPs, NP-KAg, and NP-M. $t b$ WCL were 480 $\pm 53,520 \pm 41$, and $650 \pm 98$ nm, respectively. Further, $85 \%$ of sham NPs, $92 \%$ of NP-M. $t b \mathrm{WCL}$, and $78 \%$ of NP-KAg were in the size range of 400-700 $\mathrm{nm}$. Interestingly, there was no difference among all three NPs with respect to surface electrostatic potential $(-26 \mathrm{mV})$ measured by zeta potential, indicating that differential surface charges of entrapped proteins did not influence the net electrostatic potential of finally formed different NPs.

After reconstitution of NPs entrapped with any agents in PBS, all the surface-associated agents will release immediately into the solution at time zero, and this is called burst release. ${ }^{43}$ In freshly prepared (just 2 weeks old) NP-KAg, the burst release was $9.5 \%$, and after 24 hours of reconstitution, $30.5 \%$ of protein was released (Figure 1B). Further, after 30 days, $61 \%$ of the entrapped vaccine protein was released (Figure 1B), and from the unlysed NP-KAg the remaining $39 \%$ of viral protein was recovered. In stored NP-KAg (1 year old), 13.6\% burst release and $76 \%$ of released proteins at 30 days were detected. This suggested that PLGA NPs stably retain the entrapped vaccine proteins for more than 1 year, and allow sustained pulse release of entrapped vaccine Ags under normal physiological conditions over a period of several weeks.

PRRSV infects only pigs, and the virus mainly infects PAM. Treatment of PAM cells with unentrapped KAg over a period of 24 hours resulted in negligible uptake into the cells (Figure 1C, i). In contrast, uptake of NP-KAg by PAM cells started as early as 5 minutes posttreatment and reached the peak by 30 minutes, followed by gradual reduction in fluorescence signals after 3 hours posttreatment (Figure 1C, ii), which might be attributed to degradation of released vaccine Ags from NPs inside the PAM cells. Sham NP-treated and untreated PAM cells did not show any immunofluorescence signals (Figure 1C, iii and iv), while the control PRRSVinfected MARC 145 cells had virus-specific green signals (Figure 1C, v).

\section{Enhanced production of PRRSV-specific IgG in the blood of adjuvanted NP-KAg-immunized pigs}

PRRSV infection in pigs induces massive B-cell polyclonal lymphoplasia, resulting in hypergammaglobulinemia. ${ }^{44}$ Our results indicated that total $\operatorname{IgM}, \operatorname{IgG}$, and $\operatorname{IgA}$ levels in the plasma were comparable in all the virus-challenged pig 

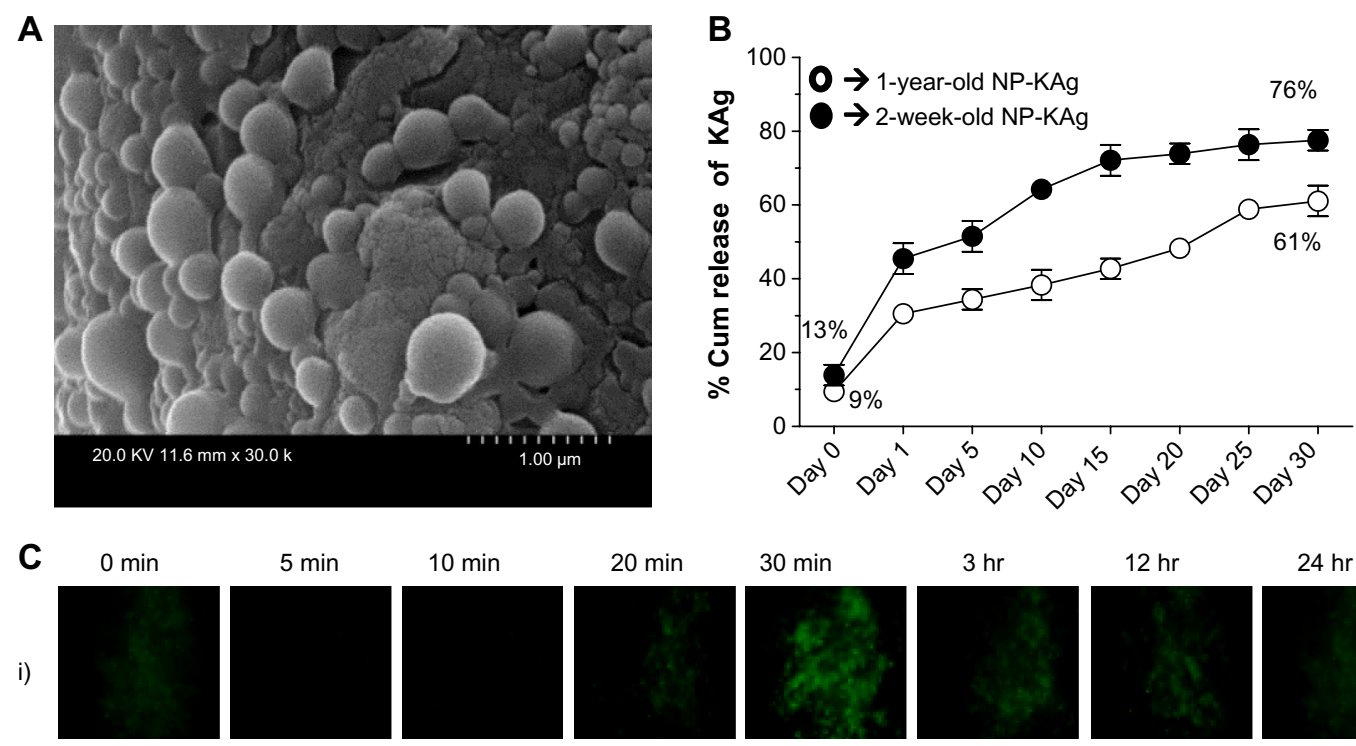

$24 \mathrm{hr}$

ii)
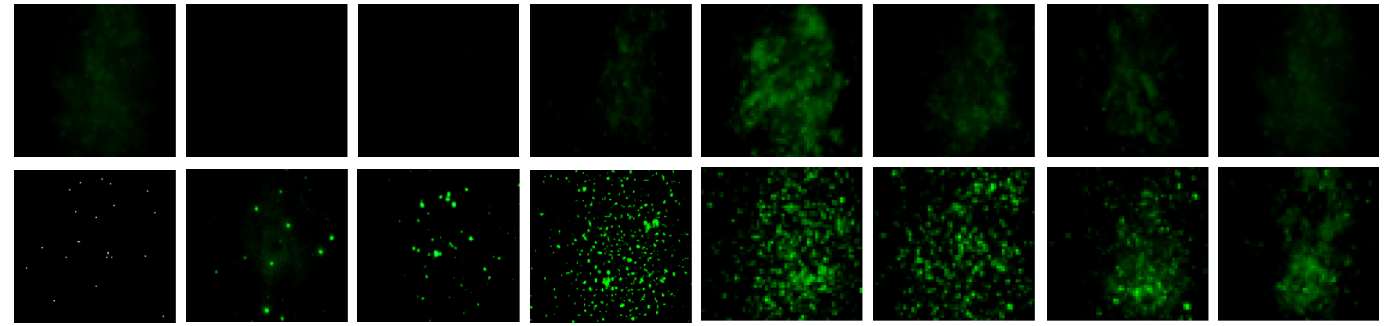

iii)
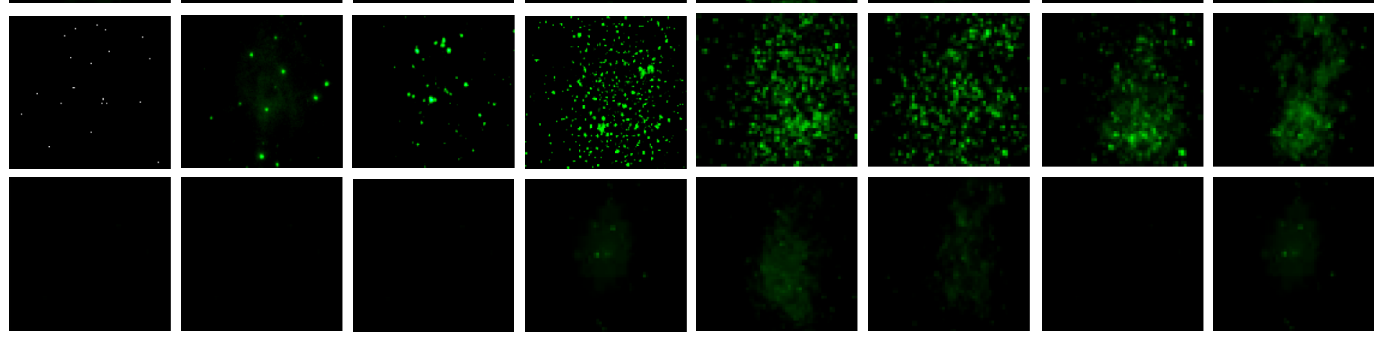

iv)

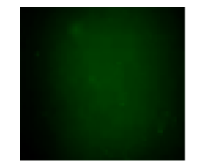

v)

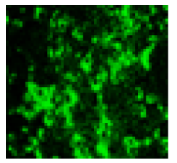

Figure I (A-C) In vitro characterization of (PRRSV) KAg-entrapped poly(lactic-co-glycolic) acid nanoparticles. (A) Picture taken with Philips XL30-FEG SEM at 20 kV with 30,000 $\times$ magnification. (B) PRRSV protein-release profile from NP-KAg was performed under normal physiological conditions. Each symbol indicates the mean of two experimental values \pm standard error of mean. (C) Uptake of NP-KAg by PAM cells at indicated time points posttreatment. Each immunofluorescence picture is a representative of indicated time point posttreatment: (i) KAg; (ii) NP-KAg; (iii) sham NPs; (iv) untreated PAM cells; (v) PRRSV (VR2332)-infected MARC I45 cells. Similar results were obtained in another two independent experiments.

Abbreviations: PRRSV, porcine reproductive and respiratory syndrome virus; KAg, killed/inactivated antigen; NP-KAg, nanoparticle-entrapped inactivated PRRSV vaccine; PAM, porcine alveolar macrophage; cum, cumulative; SEM, scanning electron microscope; NP, nanoparticle.

groups (data not shown). The PRRSV-specific IgG response was significantly higher in the plasma of group 6 pigs that received the low dose $(100 \mu \mathrm{g} / \mathrm{pig})$ compared to group 2 from PC day 0 to 15 , and compared to groups 3 and 5 at PC day 6 and 10, respectively (Figure 2A). In the high $(500 \mu \mathrm{g} / \mathrm{pig})$-dose vaccine category, group 6 pigs had significantly higher virus-specific IgG titer compared to group 2 at all the tested PC days, compared to group 3 at PCs day 0 and 6 , and compared to group 5 at PCs day 0,6 , and 15 (Figure 2B). Furthermore, we evaluated PRRSV-specific IgG response against recombinant structural proteins, and found comparable levels of IgG titers in all the pig groups against viral surface glycoproteins, GP5 and M (Figure 2F). PRRSV nucleocapsid (N)-protein specific IgG antibodies, however, were significantly higher in group 6 pigs compared to other tested groups (Figure $2 \mathrm{G}$ and $\mathrm{H}$ ). Overall, our results indicated significantly increased levels of PRRSV-specific antibody response in NP-KAg ${ }^{+} M$. $t b$ WCL-vaccinated pigs.

\section{Adjuvanted NP-KAg induced a balanced ThI and Th2 response}

Typically, killed vaccines elicit predominantly a Th2 response, but NP-based vaccines drive either a Th1 and Th2-balanced response or a Th1-biased response..$^{45}$ In pigs, higher levels of IgG subisotypes $\operatorname{IgG}_{1}$ and $\operatorname{IgG}_{2}$ indicate Th2- and Th1-biased responses, respectively. ${ }^{37}$ Therefore, we quantified PRRSVspecific $\operatorname{IgG}_{1}$ and $\operatorname{IgG}_{2}$ levels in the blood. The levels of PRRSV-specific $\operatorname{IgG}_{1}$ and $\mathrm{IgG}_{2}$ in plasma at PC day 0 in pig groups 2-5 remained low and comparable, but these levels were significantly higher at PC day 15 in group 6 pigs, which received a high vaccine dose compared to the other groups (Figure 3B). To assess Th2- or Th1-biased response, the 
PRRSV-specific IgG response $100 \mu \mathrm{g} / \mathrm{pig}$ groups

A

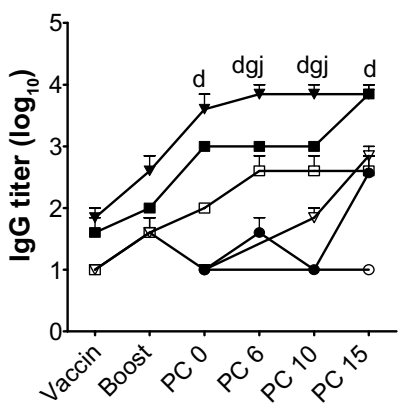

B $500 \mu g / p i g$ groups

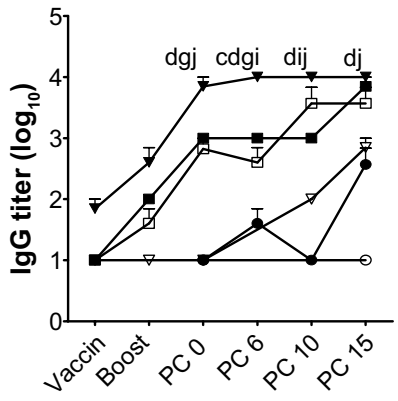

PRRSV-GP5 protein-specific lgG in plasma

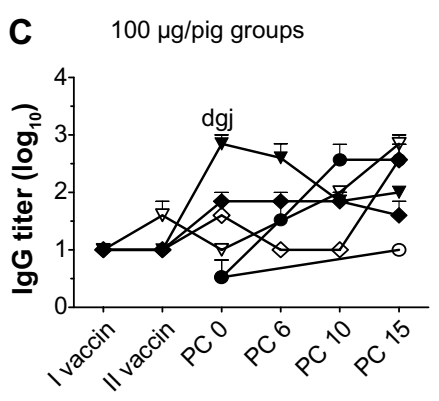

D $\quad 500 \mu \mathrm{g} /$ pig groups

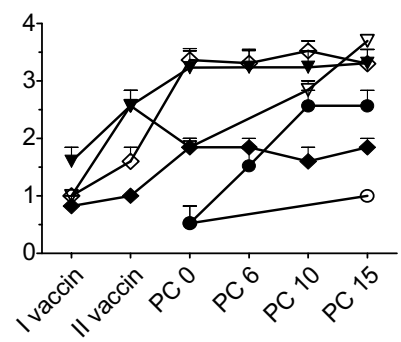

PRRSV-M protein-specific IgG in plasma
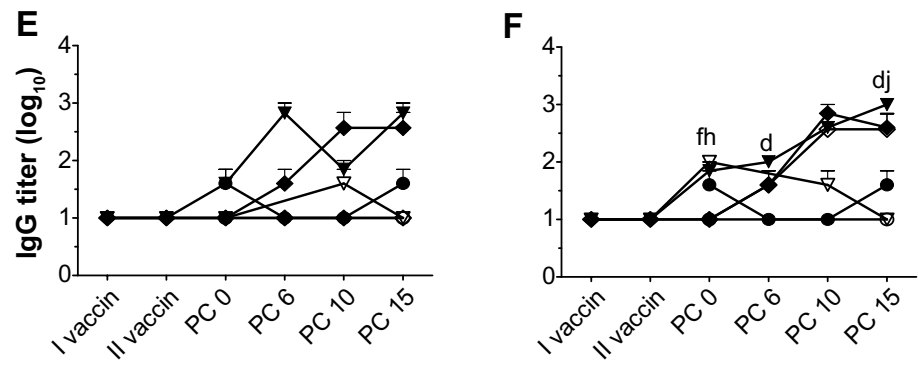

PRRSV-N protein-specific lgG in plasma

G

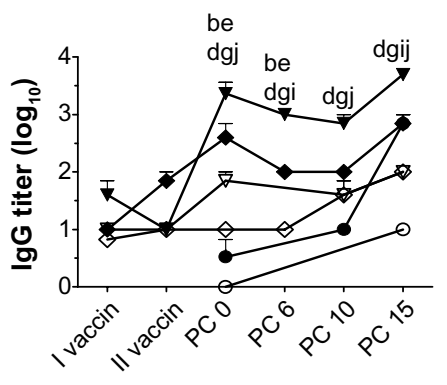

H

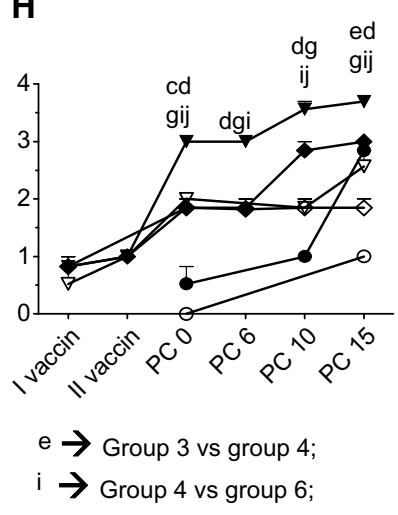

$\mathrm{b}$
$\mathrm{f} \rightarrow$ Group 2 vs group 4;
$\mathrm{j} \rightarrow$ Group 3 vs group 5;

$c \rightarrow$ Group 2 vs group 5;

$\mathrm{g} \rightarrow$ Group 3 vs group 6; $\mathrm{d} \rightarrow$ Group 2 vs group 6;

$\mathrm{h} \rightarrow$ Group 4 vs group 5 ;

Figure 2 (A-H) Significant increase in PRRSV-specific total, and M- and N-specific lgG in pigs vaccinated with adjuvanted NP-KAg. Pigs were vaccinated or unvaccinated with indicated vaccine and adjuvant combination and challenged with PRRSV MNI84. The plasma samples collected at indicated PCs were analyzed for specific lgG against PRRSV total proteins (A and B), GP5 (C and D), M (E and $\mathbf{F})$, and N (G and $\mathbf{H})$ by ELISA.

Notes: Each symbol indicates the mean PRRSV-specific lgG titer \pm SEM of three pigs of the indicated group. Lowercase letters indicate statistically significant $(P<0.05)$ differences between the two indicated pig groups.

Abbreviations: PRRSV, porcine reproductive and respiratory syndrome virus; GP5, glycoprotein 5; M, matrix protein; N, nucleocapsid protein, KAg, killed/inactivated antigen; NP-KAg, nanoparticle-entrapped inactivated PRRSV vaccine; PC, postchallenge; IgG, immunoglobulin G; ELISA, enzyme-linked immunosorbent assay; SEM, standard error of mean; chal, challenge; vaccin, vaccination; WCL, whole-cell lysate (Mycobacterium tuberculosis).

ratio of $\operatorname{IgG}_{1}: \operatorname{IgG}_{2}$ was assessed, wherein a ratio of $>1$ or $<1$ indicates a Th2- or Th1-biased response, respectively. In group 6 pigs at PC day 15, Th1- and Th2-balanced response (ratio close to 1) was detected in the plasma, while in pig groups 3 and 4, Th2-biased antibody response was detected (Figure 3D). A similar trend in antibody response was observed in pigs that received $100 \mu \mathrm{g}$ vaccine dose (Figure $3 \mathrm{~A}$ and $\mathrm{C}$ ). Thus, our data suggested that adjuvanted NP-KAg elicited Th1 and Th2-balanced immune response in pigs.

\section{Adjuvanted NP-KAg induced high-avidity PRRSV-specific antibodies}

The binding strength of heterogeneous polyclonal antibodies to cognate antigens is defined as avidity. ${ }^{38}$ At PCs day 0 and 6 , 

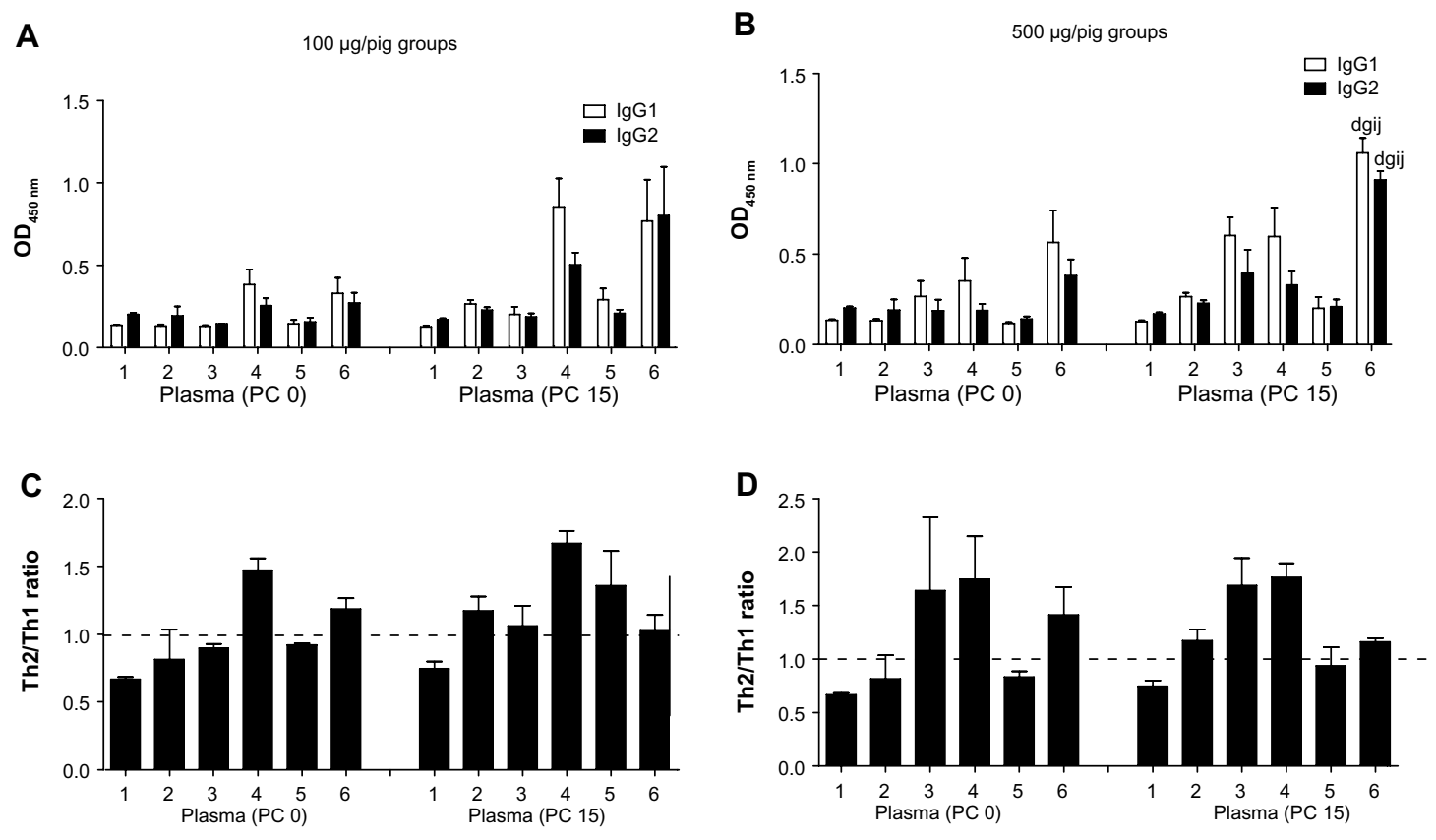

Pig groups

Pig groups

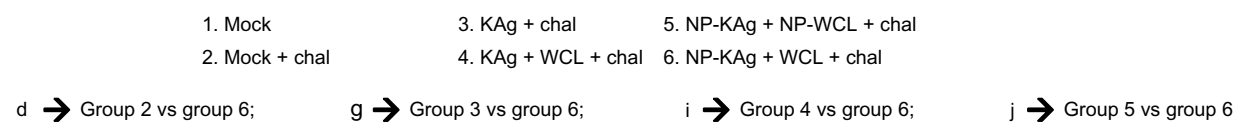

Figure 3 (A-D) Balanced ThI-Th2 antibody levels in pigs vaccinated with adjuvanted NP-KAg vaccine. Pigs were vaccinated or unvaccinated with indicated vaccine and

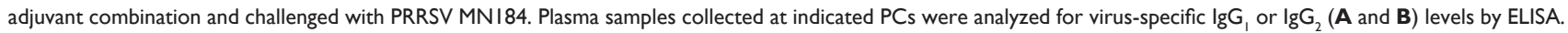
The ratio of Th2:ThI response was estimated (C and $\mathbf{D})$. Each bar/symbol indicates the mean titer/average OD value/ratio of indicated antibody types from three pigs \pm SEM. Lowercase letters indicate statistically significant $(P<0.05)$ differences between the two indicated pig groups.

Abbreviations: PRRSV, porcine reproductive and respiratory syndrome virus; KAg, killed/inactivated antigen; NP-KAg, nanoparticle-entrapped inactivated PRRSV vaccine; Th, T-helper; PC, postchallenge; IgG, immunoglobulin G; ELISA, enzyme-linked immunosorbent assay; OD, optical density; SEM, standard error of mean; WCL, whole-cell lysate (Mycobacterium tuberculosis); chal, challenge.

there were no differences in avidity of IgG in plasma among all the tested groups (Figure 4A, B, E and F). However, it was significantly higher in pig groups 4 and 6 compared to groups 2,3 , and 5 in pigs that received a low dose of vaccine, and compared to groups 2 and 5 in high-dose groups, respectively (Figure 4C and G). Overall, these data suggested that PRRSVspecific antibodies with enhanced avidity were produced at PC day 15 in adjuvanted NP-KAg vaccinated pigs.

\section{Cross-protective PRRSV-neutralization response was elicited by adjuvanted $\mathrm{NP}-\mathrm{KAg}$}

Neutralizing antibodies may play an important role in the clearance of PRRSV infection, ${ }^{46}$ and a few reports have debated the importance of VN antibodies in PRRSV clearance due to the absence of viremia in some pigs prior to detection of $\mathrm{VN}$ antibodies in serum. ${ }^{10}$ In our study, the plasma samples of group 6 pigs (at both the vaccine doses) had significantly higher $\mathrm{VN}$ titers compared to other tested groups (Figure 4D and H). In group 6 pigs, compared to the low-dose vaccine, the high-dose vaccine elicited a steady increase in VN titers (Figure 4H). VN titers against PRRSV 1-4-4 and SD03-15 strains remained undetectable in the plasma until PC day 10, and in group 6 pigs, which received the high dose of vaccine, a VN titer of eight against SD03-15 was detected at PC day 15 (data not shown). These results indicated that adjuvanted NP-KAg has the potential to elicit a broadly cross-reactive neutralizing antibody response.

\section{Downregulated proinflammatory and immunosuppressive and upregulated Th2 cytokine response in adjuvanted NP-KAg-inoculated pigs}

The cytokine IL-4 is an important indicator of Th2 response. We observed significantly increased secretion of IL-4 in restimulated PBMCs of group 6 pigs, which received the high dose of vaccine, compared to all other tested groups (Figure 5A and B). Secretion of the proinflammatory cytokine 


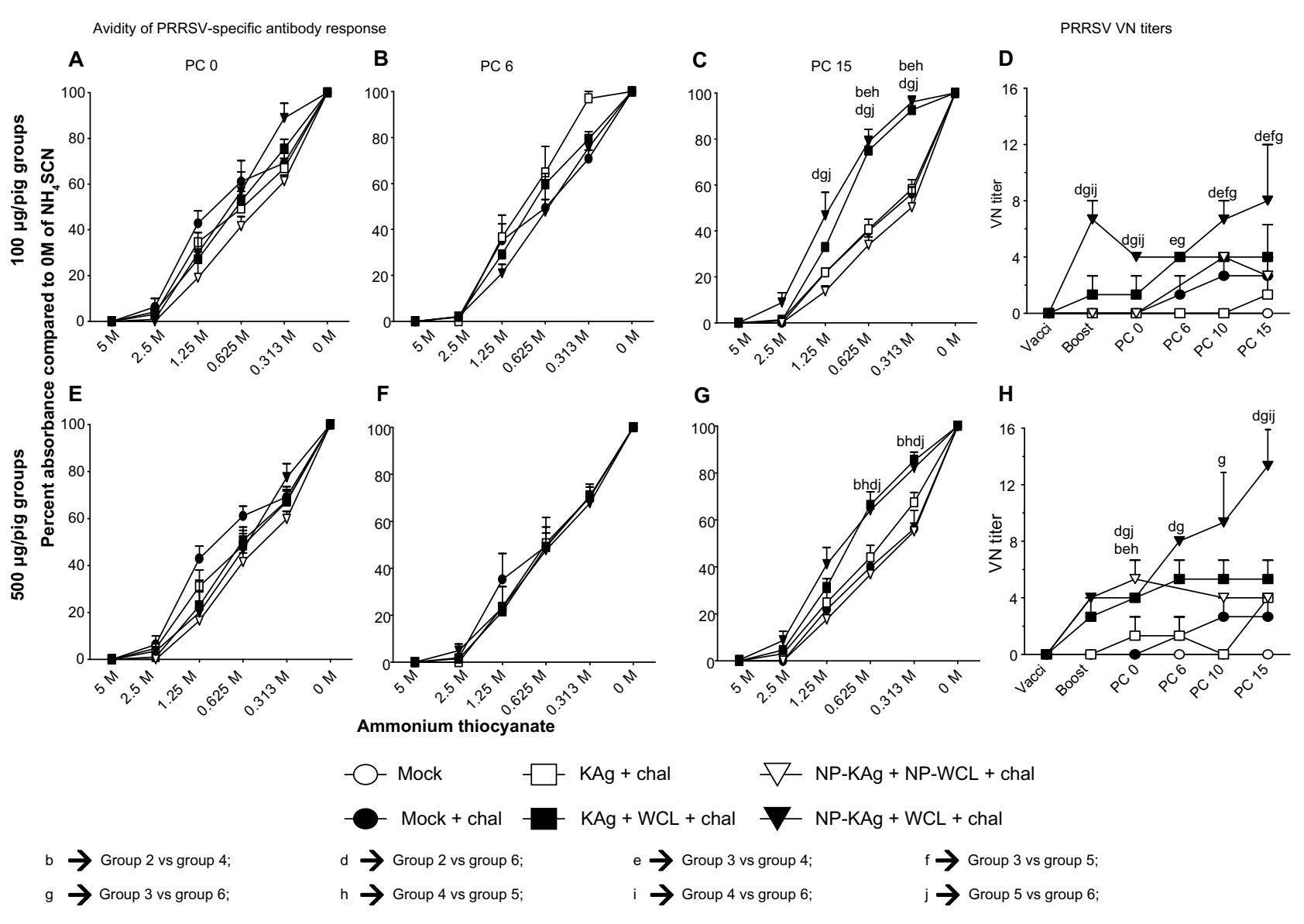

Figure $4(\mathbf{A}-\mathbf{H})$ High-avidity PRRSV specific and virus-neutralizing (VN) antibodies were produced in pigs vaccinated with adjuvanted NP-KAg. Pigs were vaccinated or unvaccinated with indicated vaccine and adjuvant combination and challenged with PRRSV MNI84. The plasma samples collected from pigs of I00 $\mu g$ per pig vaccine dose (A-C) or $500 \mu \mathrm{g}$ dose category (E-G) on the day of challenge (PC 0), followed by PC 6 and PC I5 (day of necropsy), were analyzed for avidity of PRRSV-specific IgG by ELISA. Each symbol indicates the mean of percentage absorbance compared to no ammonium thiocyanate $(0 \mathrm{M}) \pm \mathrm{SEM}$ of three pigs. The VN antibody titers in the plasma samples of $100 \mu \mathrm{g}$ per pig vaccine dose (D) or $500 \mu \mathrm{g}$ dose category $(\mathbf{H})$ were analyzed by indirect immunofluorescence assay. Each symbol in the line graph indicates the average $\mathrm{VN}$ titer of three pigs \pm SEM at indicated time point of blood collection. Lowercase letters indicate statistically significant $(P<0.05)$ differences between the two indicated groups of pigs.

Abbreviations: PRRSV, porcine reproductive and respiratory syndrome virus; KAg, killed/inactivated antigen; NP-KAg, nanoparticle-entrapped inactivated PRRSV vaccine; PC, postchallenge; IgG, immunoglobulin G; ELISA, enzyme-linked immunosorbent assay; OD, optical density; SEM, standard error of mean; vacci, vaccine; chal, challenge; WCL, whole-cell lysate (Mycobacterium tuberculosis).

IL-6 by restimulated PBMCs of the high-dose group 6 pigs was significantly reduced compared to group 2 animals (Figure 5D). Interestingly, secretion of the immunosuppressive cytokine IL-10 by PBMCs in a recall response was significantly reduced in group 6 pigs, compared to groups 2 and 3 at either vaccine dose (Figure 5E and F).

\section{Enhanced frequency of IFN $\gamma$-secreting lymphocytes and APCs in adjuvanted NP-KAg-immunized pigs}

PBMCs isolated from vaccinated, virus-challenged pigs were immunostained and analyzed to determine the frequency of lymphoid and myeloid immune cells, and IFN $\gamma^{+}$lymphocyte subsets. Comparative responses of cells unstimulated or restimulated with MN184 Ags helped to detect virus-specific lymphocyte responses. PRRSV antigen-specific recall IFN $\gamma$ response was not detectable in the $\mathrm{CD} 4^{+}$lymphocyte subset (Figure 6A). However, in group 6 pigs (both vaccine doses) a significant increase in IFN $\gamma^{+} \mathrm{CD} 8^{+}$lymphocyte response in stimulated compared to unstimulated cells was detected (Figure 6B), suggesting that $\mathrm{CD} 8^{+}$cells were primed adequately in vivo in group 6 pigs. Irrespective of in vitro stimulation of lymphocytes in pig groups 4,5 , and 6 , there was an increase in the frequency of IFN $\gamma^{+}$lymphocyte subsets like $\mathrm{CD} 56^{+}$natural killer (NK) cells (Figure 6A-C). PRRSV-antigen stimulation in group 6 pigs showed significantly increased frequency of total IFN $\gamma$-producing cells (Figure 6D and E) at both vaccine doses. When the virus-specific lymphocyte response was compared among the tested pig groups in stimulated cells, the high-dose group 6 pigs had significantly increased IFN $\gamma^{+} \mathrm{CD} 4^{+} \mathrm{CD} 8^{-}$and $\mathrm{IFN} \gamma^{+} \mathrm{CD} 8^{+} \mathrm{CD} 4^{-}$cells compared to group 2 and groups 2 and 3, respectively (Figure $6 \mathrm{~N}$ and $\mathrm{O}$ ). 
Restimulated PBMCs (PC 15)

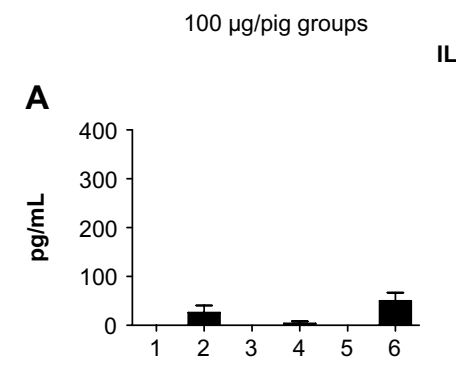

IL-6

IL-4

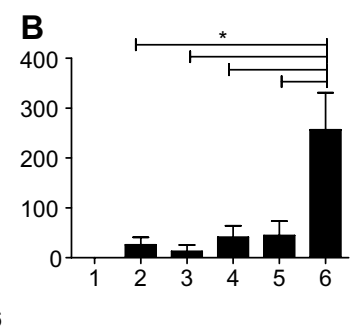

C

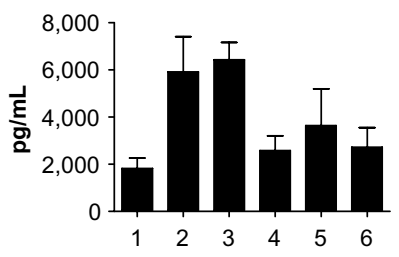

D

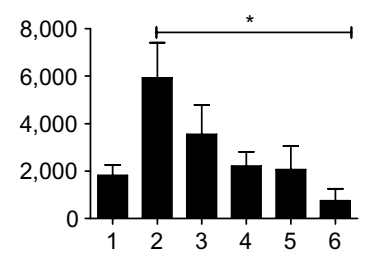

IL-10

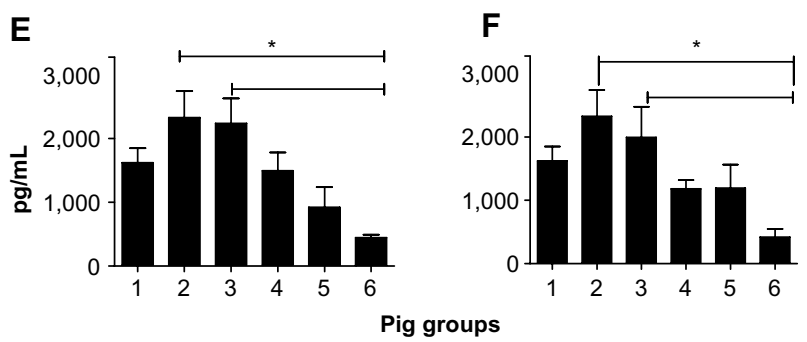
1. Mock
3. $\mathrm{KAg}+$ chal
5. NP-KAg + NP-WCL + chal
2. Mock + chal
4. $\mathrm{KAg}+\mathrm{WCL}+$ chal $6 . \mathrm{NP}-\mathrm{KAg}+\mathrm{WCL}+$ chal

Figure 5 (A-F) Upregulated Th2 and downregulated proinflammatory and immunosuppressive cytokines in pigs intranasally vaccinated with adjuvanted NP-KAg. Pigs were vaccinated ( 100 or $500 \mu g$ per pig dose) or unvaccinated with indicated vaccine and adjuvant combination and challenged with PRRSV MNI84. The culture supernatants collected from post-48-hour PRRSV MNI84 antigen $(50 \mu \mathrm{g} / \mathrm{mL})$-stimulated or unstimulated PBMCs were subjected for estimation of Th2 cytokine IL-4 (A and B), innate proinflammatory cytokine IL-6 (C and D), and immunosuppressive cytokine IL-I0 (E and F) by ELISA. Each bar indicates the average levels of indicated cytokine obtained after subtracting from the background levels of three pigs \pm SEM. Stars indicate statistically significant $(P<0.05)$ difference between the two indicated pig groups.

Abbreviations: PRRSV, porcine reproductive and respiratory syndrome virus; $\mathrm{KAg}$, killed/inactivated antigen; NP-KAg, nanoparticle-entrapped inactivated PRRSV vaccine; Th, T-helper; PC, postchallenge; ELISA, enzyme-linked immunosorbent assay; PBMC, peripheral blood mononuclear cell; IL, interleukin; SEM, standard error of mean; chal, challenge; WCL, whole-cell lysate (Mycobacterium tuberculosis).

The IFN $\gamma^{+} \mathrm{CD} 4^{+} \mathrm{CD} 8^{+}$cells were significantly higher in group 6 pigs compared to groups 3 and 5; and a similar trend was also observed in group 2 pigs (Figure 6P). An increased frequency of activated $\gamma \delta$ T cells in group 6 pigs was detected compared to other groups (Table 2b). Significantly increased IFN $\gamma^{+} \gamma \delta$ T-cell population in group 6 pigs was detected compared to group 2 pigs (Figure 6Q). Similar trends in IFN $\gamma^{+}$cells were observed in the low-dose pigs, but the data were not statistically significant (Figure 6F-I).

Although there was no significant difference in total NK $\left(\mathrm{CD}^{+} 6^{+}\right)$cell frequency (Figure 6J and R), a significant increase in IFN $\gamma^{+} \mathrm{NK}$ cell frequency was detected in pig groups 5 and 6 compared to other tested groups (Figure $6 \mathrm{~K}$ and $\mathrm{S}$ ). In addition, the dendritic cell (DC)-rich population $\left(\mathrm{CD} 172^{+} \mathrm{CD} 11 \mathrm{c}^{+} \mathrm{SLAII}^{+}\right)$was significantly higher only in group 6 pigs that received a high dose of vaccine compared to all other tested groups (Figure 6U).

\section{In adjuvanted NP-KAg-vaccinated pigs, detectable replicating PRRSV (but not viral RNA) was absent}

In order to assess the efficacy of our vaccine combinations, viral clearance was estimated in heterologous PRRSVchallenged pigs. In the blood of pig groups 4, 5, and 6 , which received the low-dose vaccine, a significantly reduced PRRSV titer was detected compared to groups 2 and 3 at PC day 10 (Figure 7A). In group 6 pigs, which received the high dose of vaccine, detectable replicating PRRSV was completely absent in the blood of virus-challenged pigs at all the tested PCs day (Figure 7B). However, the PRRSV RNA copies in the plasma were two- to threefold less in group 6 pigs compared to other groups at PC day 15 (Figure 7C and D).

\section{Discussion}

The ability to stimulate herd immunity is the hallmark of mucosal vaccines, because sufficient levels of pathogenspecific humoral and cell-mediated immune responses are elicited simultaneously at both mucosal and systemic sites, helping to neutralize infectious virus effectively, reduce virulence, and limit disease transmission. ${ }^{7}$ So far, the PRRSV-specific response induced by widely used vaccines (administered by the parenteral route) has failed to protect pigs completely against infections caused by heterologous field strains and reinfections. ${ }^{47,48}$ Since PRRSV is primarily a respiratory tract pathogen, intranasal delivery of vaccines appears to be advantageous. Among the mucosal routes, intranasal delivery of NP-based vaccines induces higher and more prolonged duration of both $\operatorname{IgG}$ and $\operatorname{IgA}$ antibody responses compared to rectal, oral, and intramuscular routes of immunization. ${ }^{45}$

PLGA NPs have the ability to mediate activation, maturation, and antigen presentation by APCs. ${ }^{49}$ They facilitate sustained release of vaccine Ags and mediate induction of robust B- and T-cell responses. ${ }^{50}$ We used PLGA $(75: 25)$ to entrap UV-inactivated PRRSV (VR2332) Ags. The observed in vitro vaccine protein-release profile from NP-KAg was comparable to another study. ${ }^{51}$ Size and surface characteristics of NPs play an important role in opsonization and clearance 


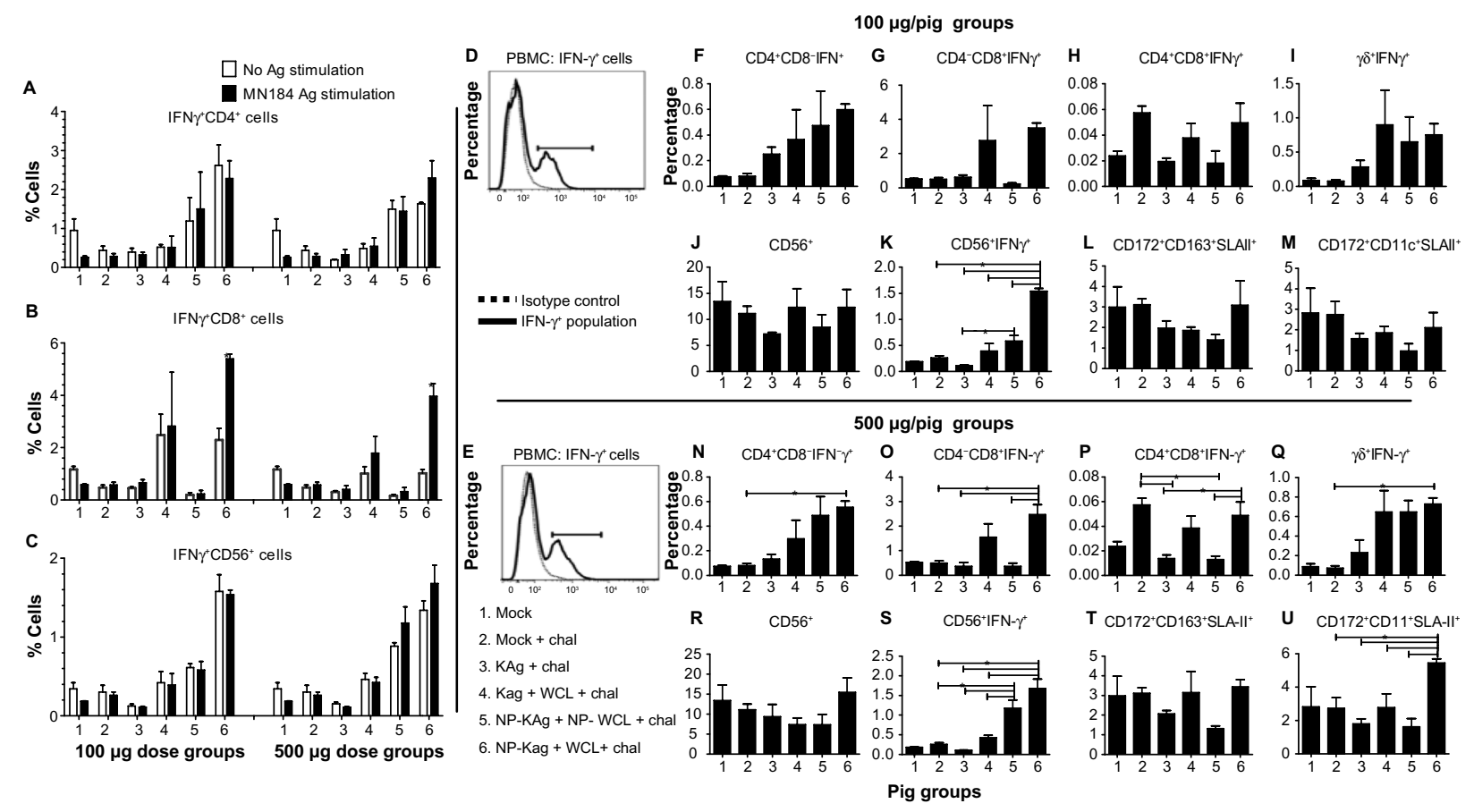

Figure $6(\mathbf{A}-\mathbf{U})$ Significantly increased IFN- $\gamma$-secreting lymphocyte subsets and APCs in the blood of pigs vaccinated with adjuvanted NP-KAg vaccine. Pigs were vaccinated ( 100 or $500 \mu \mathrm{g}$ per pig dose) or unvaccinated with indicated vaccine and adjuvant combination and challenged with PRRSV MNI84. (A-C) Unstimulated or stimulated PBMCs with PRRSV MNI84 Ags were immunostained using indicated cell-surface markers and with intracellular IFN- $\gamma$ and analyzed by flow cytometry. Representative histogram of IFN- $\gamma^{+}$cells present in the PBMCs (D and E). Dotted line - isotype control; solid line - IFN- $\gamma^{+}$-specific staining. Only stimulated PBMCs with PRRSV MNI84 Ags were immunostained using indicated cell-surface markers to show IFN- $\gamma^{+}$lymphocyte subsets. (F and $\left.\mathbf{N}\right)$ CD4+CD8-IFN- $\gamma^{+}$; (G and $\left.\mathbf{O}\right)$ CD4-CD8 ${ }^{+}$IFN- $\gamma^{+} ;(\mathbf{H}$ and $\mathbf{P})$ CD4+CD8 ${ }^{+}$IFN- $\gamma^{+}$; (I and $\left.\mathbf{Q}\right) \gamma \delta^{+}$IFN- $\gamma^{+}$; $(\mathbf{J}$ and $\mathbf{R})$ NK $\left(\mathrm{CD} 56^{+}\right)$; and (K and $\left.\mathbf{S}\right)$ CD56 IFN- $\gamma^{+}$cells were analyzed at PC I5. Also, APC populations - macrophages-rich population $\left(\mathrm{CDI} 72^{+} \mathrm{CDI} 63^{+} \mathrm{SLA}-\mathrm{II}^{+}\right)(\mathbf{L}$ and $\mathbf{T})$, and DC-rich population (CDI72+CDI I c $\left.{ }^{+} \mathrm{SLA}-\mathrm{II}^{+}\right)(\mathbf{M}$ and $\mathbf{U})$ - were analyzed. Each bar indicates the average frequency of indicated cells from three pigs \pm SEM. Asterisks indicate statistically significant $(P<0.05)$ difference between the two indicated pig groups. The unpaired $t$-test was applied to compare the data of only A-C, and for the other data one-way analysis of variance followed by Tukey's $t$-test was used.

Abbreviations: IFN, interferon; APC, antigen-presenting cell; CD, cluster of differentiation; PRRSV, porcine reproductive and respiratory syndrome virus; KAg, killed/inactivated antigen; NP-KAg, nanoparticle-entrapped inactivated PRRSV vaccine; PC, postchallenge; PBMC, peripheral blood mononuclear cell; IL, interleukin; NK, natural killer; SLA, swine leukocyte antigen; DC, dendritic cell; SEM, standard error of mean; chal, challenge; WCL, whole-cell lysate (Mycobacterium tuberculosis); Ag, antigen; Mf, macrophage.

kinetics. $^{52}$ The size range of NP-KAg was $400-700 \mathrm{~nm}$ in diameter, which is ideal for uptake by mucosal $\mathrm{M}$ cells and APCs. ${ }^{53}$ With an aim to enhance immunogenicity of NP$\mathrm{KAg}$ vaccine, we incorporated a few reagents in the vaccine compared to our earlier study. ${ }^{13,30}$ Such changes in NP-KAg vaccine were known to provide the hydrophilic nature (contributed by polaxamer 188) to NPs, facilitating easy uptake of NPs by APCs. ${ }^{54}$ Sucrose was used as a protein stabilizer, and $\mathrm{Mg}(\mathrm{OH})_{2}$ helps to buffer the acidic $\mathrm{pH}$ generated during hydrolysis of PLGA inside the APCs. ${ }^{55}$ A similar modified NP vaccine containing human immunodeficiency peptides delivered intranasally to mice elicits enhanced and prolonged IgG and IgA antibody responses. ${ }^{45}$

Compared to other micro/nanoparticles, PLGA releases the entrapped antigen at a much slower rate and elicits robust effector and memory immune responses. ${ }^{56}$ Entrapped PRRSV antigens were retained inside the NPs for several days under physiological conditions, indicating the efficiency of NP-KAg vaccine to preserve the entrapped Ags in vivo for a prolonged period or until phagocytosed by APCs. A recent study has shown that the magnitude of CD4 and CD8 T-cell responses is dependent on the duration of available vaccine Ags, as effector T cells (also to a lesser extent memory $T$ cells) require sustained antigenic stimulation for their expansion. ${ }^{57}$ PLGA NPs promote cross-presentation of vaccine antigens due to their phagosome-disruptive properties inside DCs and macrophages, resulting in enhanced delivery of antigens to the cytosol for major histocompatibility complex class I loading and increased $\mathrm{CD}^{+}$T-cell effector response. ${ }^{58-63}$ It also helps in the generation of memory $\mathrm{CD}^{+} \mathrm{T}$-cell response and clearance of invading pathogens. ${ }^{56}$ Consistent with the other studies, rapid uptake of NP-KAg vaccine by PAM cells was noticed, suggesting the ability of PLGA NPs to deliver vaccine Ags rapidly and efficiently to target cells. ${ }^{50,64}$

Clinically, only mock (group 2) and KAg (group 3) vaccinated, MN184 virus-challenged pigs had irregular fever with reduced feed intake during the first 2 weeks postchallenge, and such physiological changes were absent in other pig groups. Though the MN184 virus is a virulent field 
Table 2 The frequency of activated lymphocyte subsets in vaccine trial pigs

\begin{tabular}{|c|c|c|c|c|c|}
\hline $\begin{array}{l}\text { Mock } \\
\text { (I) }\end{array}$ & $\begin{array}{l}\text { Mock + Ch } \\
\text { (2) }\end{array}$ & $\begin{array}{l}\mathrm{KAg}+\mathrm{Ch} \\
\text { (3) }\end{array}$ & $\begin{array}{l}\mathrm{KAg}+ \\
\mathrm{WCL}+\mathrm{Ch} \\
\text { (4) }\end{array}$ & $\begin{array}{l}\text { NP (KAg + } \\
\text { WCL) + Ch } \\
(5)\end{array}$ & $\begin{array}{l}\text { NP-KAg + } \\
\text { WCL + Ch } \\
\text { (6) }\end{array}$ \\
\hline \multicolumn{6}{|c|}{ sse category } \\
\hline $5.0 \pm 1.3$ & $7.7 \pm 1.7$ & $10.7 \pm 6.2$ & $17.8 \pm 3.0$ & $4.4 I \pm I .62$ & $12.2 \pm 1.0$ \\
\hline $6.1 \pm 2.8$ & $6.9 \pm 1.1$ & $2.6 \pm 1.4$ & $3.3 \pm 0.2$ & $1.68 \pm 1.19$ & $5.2 \pm 2.1$ \\
\hline $0.2 \pm 0.1$ & $0.3 \pm 0.1$ & $0.2 \pm 0.1$ & $1.0 \pm 0.5$ & $0.54 \pm 0.16$ & $0.8 \pm 0.2$ \\
\hline \multicolumn{6}{|c|}{ se category } \\
\hline $5.0 \pm 1.3$ & $7.7 \pm 1.7$ & $13.3 \pm 6.2$ & $19.3 \pm 7.4$ & $5.7 \pm 0.7$ & $31.3 \pm 13.6$ \\
\hline $6.1 \pm 2.8$ & $6.9 \pm 1.1$ & $4.1 \pm 0.7$ & $1.8 \pm 1.0$ & $1.6 \pm 0.4$ & $7.3 \pm 3.4$ \\
\hline $0.2 \pm 0.1$ & $0.3 \pm 0.1$ & $0.2 \pm 0.1$ & $0.8 \pm 0.3$ & $1.3 \pm 0.3$ & $2.3 \pm 0.8^{\mathrm{dg}}$ \\
\hline
\end{tabular}

Notes: Pigs were vaccinated or unvaccinated with indicated vaccine and adjuvant combination and challenged with PRRSV MNI84. Indicated activated (CD25+) lymphocyte subsets were analyzed in the PBMCs on the day of necropsy. Each number is an average percentage of indicated immune cell frequency of three pigs \pm SEM. Lower case entries indicate statistically significant $(P<0.05)$ difference between the two indicated pig groups.

Abbreviations: Ch, challenge; KAg, killed antigen; WCL, whole-cell lysate (Mycobacterium tuberculosis); NP, nanoparticle; CD, cluster of differentiation; PRRSV, porcine reproductive and respiratory syndrome virus; PBMC, peripheral blood mononuclear cell; SEM, standard error of mean; NP-KAg, nanoparticle-entrapped inactivated PRRSV vaccine.

strain, ${ }^{65}$ absence of pronounced clinical PRRS symptoms in virus-challenged pigs could be due to use of a repeated tissue culture-passaged virus. It is desirable to have both vaccine Ags and adjuvant in the same NPs, considering the added benefits of delivery of antigen and adjuvant to the same APC. However, we entrapped them separately, because it is difficult to differentially quantify entrapped vaccine proteins from the adjuvant, as the $M$. $t b$ WCL principally contains proteins. However, in future, we will evaluate such combined entrapped vaccines.

We have demonstrated that our $M$. $t b$ WCL adjuvanted NP-KAg vaccine formulation augmented cross-protective immune responses against a heterologous PRRSV, confirming the benefits of an NP-mediated vaccine-delivery system in pigs, consistent with others findings. ${ }^{7,29,66-68}$ Overall, cross-protective responses elicited by NP-KAg plus $M$. $t b$ WCL formulation in pigs were indicated by the following important immune correlates: 1) absence of detectable challenged heterologous replicating PRRSV from PC day 6, associated with a threefold reduction in viral RNA load; 2) increased levels of PRRSV VN titers, associated with increased virus-specific antibody response and enhanced antibody avidity with time; 3) balanced Th1 and Th2 responses; and 4) significantly increased frequency of IFN $\gamma$-secreting cells and downregulated secretion of the immunosuppressive cytokine IL-10.

Comparable levels of total quantity of antibodies were detected in all the PRRSV-challenged pigs, but significantly enhanced levels of anti-PRRSV antibody response were detected only in adjuvanted NP-KAg-vaccinated pigs. Enhanced avidity of polyclonal antibodies in vaccinated or infected animals is positively correlated with their VN titers. ${ }^{38}$ Avidity of PRRSV-specific IgG in the plasma of group 6 pigs gradually increased, becoming significantly higher at PC day 15 in NP-KAg plus $M$. $t b$ WCL-vaccinated pigs, attributed to gradual domination of high-affinity B-cell clones. ${ }^{38}$ NPs have been shown to interact with pathogenrecognition receptors on APCs (especially B cells), leading to affinity maturation and production of high-avidity antibodies. $^{69}$

Virus-specific neutralizing antibodies play an important role in the clearance of PRRSV viremia ${ }^{46,70-72}$ by limiting the viral uptake by target cells. ${ }^{73}$ The mean VN titer in adjuvanted NP-KAg-vaccinated pigs was higher than the proposed titer of eight, which cleared the viremia at 2 weeks postchallenge. ${ }^{46,74}$ The clearance of detectable, replicating PRRSV was absent as early as 6 days postchallenge, which could be attributed to early appearance of VN antibodies, possibly targeted against putative neutralizing epitopes present on PRRSV GP5 and M proteins. ${ }^{75}$ We will consider analyzing viral load at earlier time points in future studies. Normally, PRRSV-specific VN activity is detectable only after 3-4 weeks in infected pigs, ${ }^{76,77}$ and significantly varies with the strain of PRRSV. In adjuvanted NP-KAg-vaccinated pigs, VN titers were detectable by 1 week postchallenge and later steadily increased. Thus, using our NP-based vaccination approach, it is possible to induce high levels of long-lasting PRRSV VN titers and to elicit an effective memory response. ${ }^{56}$ Inactivated vaccines elicit predominantly Th2 responses, ${ }^{78}$ but NP-based vaccines have been shown to drive either Th1-Th2-balanced or Th1-biased responses. ${ }^{45}$ In adjuvanted NP-KAg-vaccinated pigs, a balanced Th1-Th2 response was observed, indicated by increased levels of virus-specific $\operatorname{IgG}_{1}$ and $\operatorname{IgG}_{2}$ production and enhanced IFN $\gamma$ and IL-4 responses. 
Clearance of challenged PRRSV (MN184) in blood

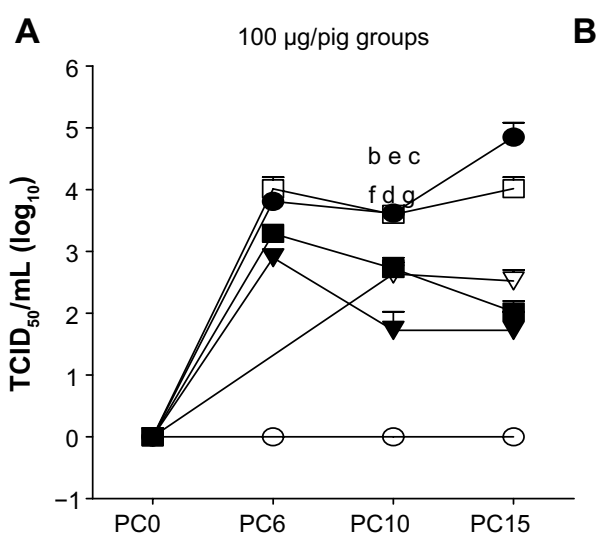

B

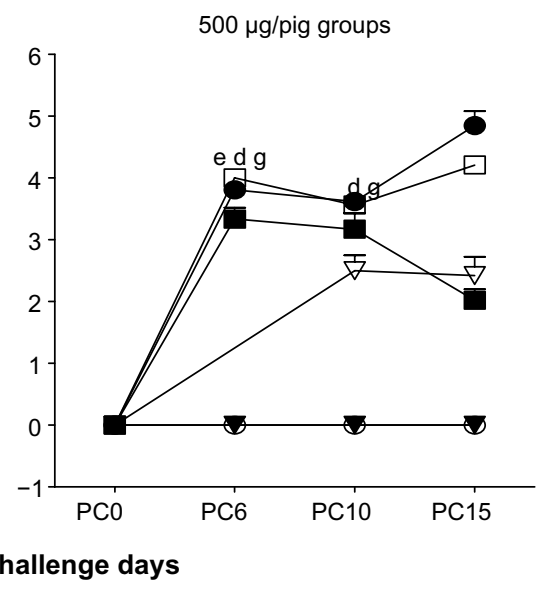

PRRSV RNA in plasma

C

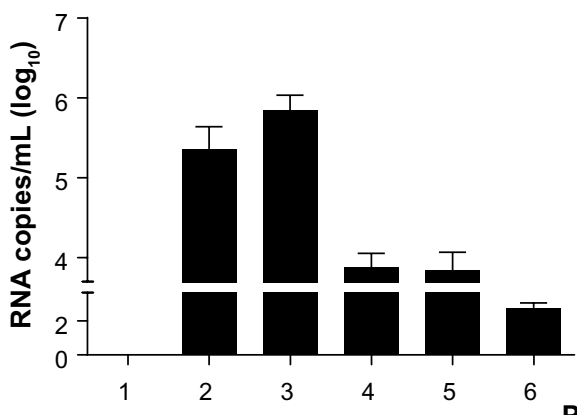

D

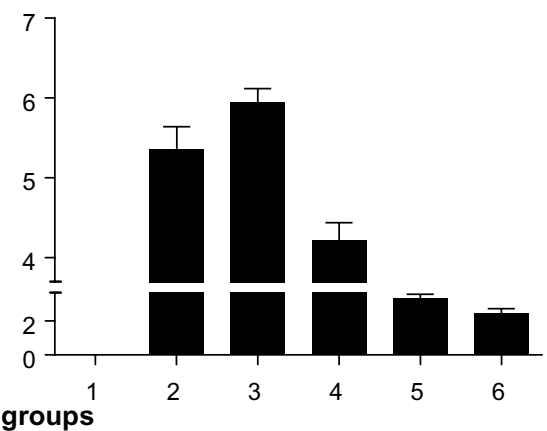

5. $\searrow-\mathrm{NP}-\mathrm{KAg}+\mathrm{NP}-\mathrm{WCL}+$ chal

6. $\checkmark \mathrm{NP}-\mathrm{KAg}+\mathrm{WCL}+$ chal

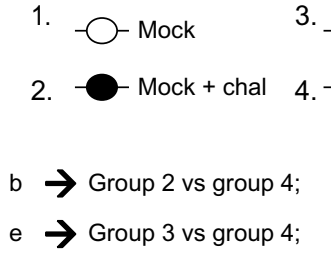

3. $-\square-\mathrm{KAg}+\mathrm{chal}$

$\mathrm{KAg}+\mathrm{WCL}+$ chal

$c \rightarrow$ Group 2 vs group 5;

$f \rightarrow$ Group 3 vs group 5 ; $d \rightarrow$ Group 2 vs group 6;

$g \rightarrow$ Group 3 vs group 6;

Figure 7 (A-D) Clearance of detectable replicating challenged PRRSV and reduced viral RNA in the blood of pigs vaccinated with adjuvanted NP-KAg vaccine. Pigs were vaccinated ( 100 or $500 \mu \mathrm{g}$ per pig dose) or unvaccinated with indicated vaccine and adjuvant combination and challenged with PRRSV MNI84. The plasma samples collected at indicated PCs were analyzed for the presence of replicating PRRSV titer by indirect immunofluorescence assay (A and B). The plasma samples collected at PC I5 were analyzed to quantify viral RNA copies by qRT-PCR (C and D). Each bar or symbol indicates the mean viral titer or viral RNA copy number of three pigs \pm SEM. Lowercase letters indicate statistically significant $(P<0.05)$ differences between the two indicated groups of pigs.

Abbreviations: PRRSV, porcine reproductive and respiratory syndrome virus; KAg, killed/inactivated antigen; NP-KAg, nanoparticle-entrapped inactivated PRRSV vaccine; RNA, ribonucleic acid; PC, postchallenge; qRT-PCR, quantitative reverse transcription polymerase chain reaction; SEM, standard error of mean, TCID, tissue-culture infective dose; WCL, whole-cell lysate (Mycobacterium tuberculosis).

Although we detected significantly increased frequency of different IFN $\gamma$-secreting lymphocyte subsets in group 6 pig PBMCs, significantly increased frequency in the restimulated compared to unstimulated cells was detected only in $\mathrm{CD}^{-}{ }^{-} \mathrm{CD} 8^{+} \mathrm{IFN} \gamma^{+}$cell population, suggesting a possible strong cytotoxic T-cell response in those pigs. Since we detected increased but comparable frequency of IFN $\gamma$-secreting cells in other lymphocyte subsets of both stimulated and unstimulated PBMCs of group 6 pigs, our data also indicate that other T-effector cells and NK cells were actively secreting IFN $\gamma$ as part of the response to the PRRSV-challenge infection in vivo. As we do not have the data on the IFN $\gamma$ cell response in pigs postvaccination (prior to challenge), it is difficult to show exclusively only the challenge virus-induced response.

We observed the necessity of immediate availability of soluble adjuvant at the site of NP-vaccine delivery, because incomplete virus clearance and inadequate immune response were detected in pigs coadministered with both vaccine Ag- and adjuvant-entrapped NPs. Our results are consistent with an earlier report, wherein 
PLGA encapsulation of vaccine Ags (hepatitis B core antigen) and adjuvant (monophosphoryl lipid A) failed to increase an antibody response. ${ }^{79}$ Another advantage of NP-based vaccines is their ability to reduce greatly the required vaccine dose. A recent study has estimated that a dose of PLGA NP-based vaccine could be reduced by as much as 63 times compared to administration of a Freund's incomplete adjuvant emulsified vaccine. ${ }^{80}$ Although in pigs vaccinated with adjuvanted NP-KAg (100 $\mu \mathrm{g} / \mathrm{pig} /$ dose) vaccine, a substantial level of immune response was elicited, the virus clearance was not satisfactory, indicating the need for a suitable vaccine dose ( $500 \mu \mathrm{g} / \mathrm{dose}$ ) for better viral clearance. PLGA-mediated vaccine-delivery systems are getting global recognition, due to their flexibility to engineer particles of any size, charge, content, and cell-targeting properties, and they have proved to be highly effective in delivery of both subunit and inactivated whole-pathogen vaccines, especially to mucosal sites. ${ }^{7}$

In conclusion, intranasal delivery of PLGA NP-entrapped inactivated PRRSV vaccine adjuvanted with soluble $M$. $t b$ WCL has the potential to induce cross-protective immune response in pigs. Future studies are aimed at elucidating the duration of cross-protective immune responses in vaccinated pigs and detection of challenge PRRSV in lymphoid tissues. In addition, fractionation of $M . t b$ WCL to identify the important component/s involved in potent adjuvant effects and evaluation of immunostimulatory effects of entrapped M. $t b$ lysate compared to soluble lysate using porcine DCs and macrophages will also be considered.

\section{Acknowledgments}

This work was supported by National Pork Board (09-213) and USDA-NIFA PRRSCAP2 (2008-55620-19132) awards to GJR. Salaries and research support were provided by state and federal funds appropriated to the Ohio Agricultural Research and Development Center, Ohio State University. We would like to thank Dr Eric Nelson for providing the VR2332 strain of PRRSV and control serum samples, and Dr Michael Murtaugh (University of Minnesota) for providing the PRRSV recombinant N, M, or GP5 proteins used in the ELISA and MN184 strain of PRRSV. We would like to thank Dr Juliette Hanson and Andrew Wright for their help in animal studies. We also thank Michele Williams for editing the manuscript.

\section{Disclosure}

The authors report no conflicts of interest in this work.

\section{References}

1. Holtkamp D, Kliebenstein J. Pork checkoff study: PRRS costs industry $\$ 664$ million annually. 2011. Available from: http://www.pork.org/ News/1265/PRRSCostsIndustry664Million.aspx. Accessed November $28,2013$.

2. Kim WI, Lee DS, Johnson W, Roof M, Cha SH, Yoon KJ. Effect of genotypic and biotypic differences among PRRS viruses on the serologic assessment of pigs for virus infection. Vet Microbiol. 2007; 123(1-3):1-14.

3. Nielsen HS, Oleksiewicz MB, Forsberg R, Stadejek T, Bøtner A, Storgaard T. Reversion of a live porcine reproductive and respiratory syndrome virus vaccine investigated by parallel mutations. J Gen Virol. 2001;82(Pt 6):1263-1272.

4. Kimman TG, Cornelissen LA, Moormann RJ, Rebel JM, Stockhofe-Zurwieden N. Challenges for porcine reproductive and respiratory syndrome virus (PRRSV) vaccinology. Vaccine. 2009;27(28): 3704-3718.

5. Ma Y, Chen Q, Ross AC. Retinoic acid and polyriboinosinic: polyribocytidylic acid stimulate robust anti-tetanus antibody production while differentially regulating type 1/type 2 cytokines and lymphocyte populations. J Immunol. 2005;174(12):7961-7969.

6. Murtaugh MP, Xiao Z, Zuckermann F. Immunological responses of swine to porcine reproductive and respiratory syndrome virus infection. Viral Immunol. 2002;15(4):533-547.

7. Lycke N. Recent progress in mucosal vaccine development: potential and limitations. Nat Rev Immunol. 2012;12(8):592-605.

8. Vanhee M, Delputte PL, Delrue I, Geldhof MF, Nauwynck HJ. Development of an experimental inactivated PRRSV vaccine that induces virus-neutralizing antibodies. Vet Res. 2009;40(6):63.

9. Wills RW, Zimmerman JJ, Yoon KJ, et al. Porcine reproductive and respiratory syndrome virus: a persistent infection. Vet Microbiol. 1997;55(1-4):231-240.

10. Darwich L, Diaz I, Mateu E. Certainties, doubts and hypotheses in porcine reproductive and respiratory syndrome virus immunobiology. Virus Res. 2010;154(1-2):123-132.

11. Kim H, Kim HK, Jung JH, et al. The assessment of efficacy of porcine reproductive respiratory syndrome virus inactivated vaccine based on the viral quantity and inactivation methods. Virol J. 2011;8:323.

12. Heegaard PM, Dedieu L, Johnson N, et al. Adjuvants and delivery systems in veterinary vaccinology: current state and future developments. Arch Virol. 2011;156(2):183-202.

13. Binjawadagi B, Dwivedi V, Manickam C, Torrelles JB, Renukaradhya GJ. Intranasal delivery of an adjuvanted modified live porcine reproductive and respiratory syndrome virus vaccine reduces ROS production. Viral Immunol. 2011;24(6):475-482.

14. Dwivedi V, Manickam C, Patterson R, et al. Cross-protective immunity to porcine reproductive and respiratory syndrome virus by intranasal delivery of a live virus vaccine with a potent adjuvant. Vaccine. 2011;29(23):4058-4066.

15. Dwivedi V, Manickam C, Patterson R, Dodson K, Weeman M, Renukaradhya GJ. Intranasal delivery of whole cell lysate of Mycobacterium tuberculosis induces protective immune responses to a modified live porcine reproductive and respiratory syndrome virus vaccine in pigs. Vaccine. 2011;29(23):4067-4076.

16. Srivastava P. Interaction of heat shock proteins with peptides and antigen presenting cells: chaperoning of the innate and adaptive immune responses. Annu Rev Immunol. 2002;20:395-425.

17. Werner GH, Maral R, Floch F, Migliore-Samour D, Jollès P. Adjuvant and immunostimulating activities of water-soluble substances extracted from Mycobacterium tuberculosis (var. hominis). Biomedicine. 1975;22(5):440-452.

18. Larson CL, Bell JF, List RH, Ribi E, Wicht WC. Symposium on Relationship of Structure of Microorganisms to Their Immunological Properties. II. Host-reactive properties of cell walls and protoplasm from mycobacteria. Bacteriol Rev. 1963;27:341-351.

19. White RG, Bernstock L, Johns RG, Lederer E. The influence of components of $M$. tuberculosis and other mycobacteria upon antibody production to ovalbumin. Immunology. 1958;1(1):54-66. 
20. Bansal K, Elluru SR, Narayana Y, et al. PE_PGRS antigens of Mycobacterium tuberculosis induce maturation and activation of human dendritic cells. J Immunol. 2010;184(7):3495-3504.

21. Harmala LA, Ingulli EG, Curtsinger JM, et al. The adjuvant effects of Mycobacterium tuberculosis heat shock protein 70 result from the rapid and prolonged activation of antigen-specific CD8+ T cells in vivo. J Immunol. 2002;169(10):5622-5629.

22. O'Hagan DT, Rahman D, McGee JP, et al. Biodegradable microparticles as controlled release antigen delivery systems. Immunology. 1991;73(2): 239-242.

23. McNeil SE. Nanotechnology for the biologist. J Leukoc Biol. 2005; 78(3):585-594.

24. Panyam J, Labhasetwar V. Biodegradable nanoparticles for drug and gene delivery to cells and tissue. Adv Drug Deliv Rev. 2003;55(3): 329-347.

25. Gregory AE, Titball R, Williamson D. Vaccine delivery using nanoparticles. Front Cell Infect Microbiol. 2013;3:13.

26. Diwan M, Elamanchili P, Cao M, Samuel J. Dose sparing of CpG oligodeoxynucleotide vaccine adjuvants by nanoparticle delivery. Curr Drug Deliv. 2004;1(4):405-412.

27. Lutsiak ME, Kwon GS, Samuel J. Biodegradable nanoparticle delivery of a Th2-biased peptide for induction of Th1 immune responses. J Pharm Pharmacol. 2006;58(6):739-747.

28. Kasturi SP, Skountzou I, Albrecht RA, et al. Programming the magnitude and persistence of antibody responses with innate immunity. Nature. 2011;470(7335):543-547.

29. Chadwick S, Kriegel C, Amiji M. Nanotechnology solutions for mucosal immunization. Adv Drug Deliv Rev. 2010;62(4-5):394-407.

30. Dwivedi V, Manickam C, Binjawadagi B, Joyappa D, Renukaradhya GJ. Biodegradable nanoparticle-entrapped vaccine induces cross-protective immune response against a virulent heterologous respiratory viral infection in pigs. PLoS One. 2012;7(12):e51794.

31. Dwivedi V, Manickam C, Binjawadagi B, Renukaradhya GJ. PLGA nanoparticle entrapped killed porcine reproductive and respiratory syndrome virus vaccine helps in viral clearance in pigs. Vet Microbiol. 2013;166(1-2):47-58.

32. Christopher-Hennings J, Holler LD, Benfield DA, Nelson EA. Detection and duration of porcine reproductive and respiratory syndrome virus in semen, serum, peripheral blood mononuclear cells, and tissues from Yorkshire, Hampshire, and Landrace boars. J Vet Diagn Invest. 2001;13(2):133-142.

33. Takayama K, Schnoes HK, Armstrong EL, Boyle RW. Site of inhibitory action of isoniazid in the synthesis of mycolic acids in Mycobacterium tuberculosis. J Lipid Res. 1975;16(4):308-317.

34. Broxmeyer HE, Christopherson K, Hangoc G, et al. CD1d expression on and regulation of murine hematopoietic stem and progenitor cells. Blood. 2012;119(24):5731-5741.

35. Saini V, Jain V, Sudheesh MS, Jaganathan KS, Murthy PK, Kohli DV. Comparison of humoral and cell-mediated immune responses to cationic PLGA microspheres containing recombinant hepatitis B antigen. Int $J$ Pharm. 2011;408(1-2):50-57.

36. Zhang L, Tian X, Zhou F. Intranasal administration of $\mathrm{CpG}$ oligonucleotides induces mucosal and systemic type 1 immune responses and adjuvant activity to porcine reproductive and respiratory syndrome killed virus vaccine in piglets in vivo. Int Immunopharmacol. 2007;7(13): 1732-1740.

37. Guo YJ, Sun SH, Zhang Y, et al. Protection of pigs against Taenia solium cysticercosis using recombinant antigen or in combination with DNA vaccine. Vaccine. 2004;22(29-30):3841-3847.

38. Thompson AL, Johnson BT, Sempowski GD, et al. Maximal adjuvant activity of nasally delivered IL-1alpha requires adjuvant-responsive $\mathrm{CD} 11 \mathrm{c}(+)$ cells and does not correlate with adjuvant-induced in vivo cytokine production. J Immunol. 2012;188(6):2834-2846.

39. Adam A, Ciorbaru R, Petit JF, Lederer E. Isolation and properties of a macromolecular, water-soluble, immuno-adjuvant fraction from the cell wall of Mycobacterium smegmatis. Proc Natl Acad Sci U S A. 1972;69(4):851-854
40. Cai HY, Alexander H, Carman S, Lloyd D, Josephson G, Maxie MG Restriction fragment length polymorphism of porcine reproductive and respiratory syndrome viruses recovered from Ontario farms, 1998-2000. J Vet Diagn Invest. 2002;14(4):343-347.

41. Fang Y, Kim DY, Ropp S, et al. Heterogeneity in Nsp2 of European-like porcine reproductive and respiratory syndrome viruses isolated in the United States. Virus Res. 2004;100(2):229-235.

42. Ito F, Fujimori H, Makino K. Factors affecting the loading efficiency of water-soluble drugs in PLGA microspheres. Colloids Surf B Biointerfaces. 2008;61(1):25-29.

43. Rawat A, Majumder QH, Ahsan F. Inhalable large porous microspheres of low molecular weight heparin: in vitro and in vivo evaluation. J Control Release. 2008;128(3):224-232.

44. Lemke CD, Haynes JS, Spaete R, et al. Lymphoid hyperplasia resulting in immune dysregulation is caused by porcine reproductive and respiratory syndrome virus infection in neonatal pigs. J Immunol. 2004;172(3): 1916-1925.

45. Manocha M, Pal PC, Chitralekha KT, et al. Enhanced mucosal and systemic immune response with intranasal immunization of mice with HIV peptides entrapped in PLG microparticles in combination with Ulex europaeus-I lectin as M cell target. Vaccine. 2005;23(48-49): 5599-5617.

46. Lopez OJ, Osorio FA. Role of neutralizing antibodies in PRRSV protective immunity. Vet Immunol Immunopathol. 2004;102(3): 155-163.

47. Labarque G, Reeth KV, Nauwynck H, Drexler C, Van Gucht S, Pensaert M. Impact of genetic diversity of European-type porcine reproductive and respiratory syndrome virus strains on vaccine efficacy. Vaccine. 2004;22(31-32):4183-4190.

48. Mengeling WL, Lager KM, Vorwald AC, Koehler KJ. Strain specificity of the immune response of pigs following vaccination with various strains of porcine reproductive and respiratory syndrome virus. Vet Microbiol. 2003;93(1):13-24.

49. Yoshida M, Babensee JE. Differential effects of agarose and poly(lacticco-glycolic acid) on dendritic cell maturation. J Biomed Mater Res A. 2006;79(2):393-408.

50. Nixon DF, Hioe C, Chen PD, et al. Synthetic peptides entrapped in microparticles can elicit cytotoxic T cell activity. Vaccine. 1996;14(16): 1523-1530.

51. Mukherjee B, Santra K, Pattnaik G, Ghosh S. Preparation, characterization and in-vitro evaluation of sustained release protein-loaded nanoparticles based on biodegradable polymers. Int J Nanomedicine. 2008;3(4):487-496.

52. Moghimi SM, Szebeni J. Stealth liposomes and long circulating nanoparticles: critical issues in pharmacokinetics, opsonization and protein-binding properties. Prog Lipid Res. 2003;42(6):463-478.

53. Kim B, Bowersock T, Griebel P, et al. Mucosal immune responses following oral immunization with rotavirus antigens encapsulated in alginate microspheres. J Control Release. 2002;85(1-3): 191-202.

54. Rajapaksa TE, Bennett KM, Hamer M, Lytle C, Rodgers VG, Lo DD. Intranasal $\mathrm{M}$ cell uptake of nanoparticles is independently influenced by targeting ligands and buffer ionic strength. J Biol Chem. 2010;285(31): 23739-23746.

55. Gupta PN, Mahor S, Rawat A, Khatri K, Goyal A, Vyas SP. Lectin anchored stabilized biodegradable nanoparticles for oral immunization 1. Development and in vitro evaluation. Int J Pharm. 2006;318(1-2): $163-173$.

56. Demento SL, Cui W, Criscione JM, et al. Role of sustained antigen release from nanoparticle vaccines in shaping the $\mathrm{T}$ cell memory phenotype. Biomaterials. 2012;33(19):4957-4964.

57. Blair DA, Turner DL, Bose TO, et al. Duration of antigen availability influences the expansion and memory differentiation of $\mathrm{T}$ cells. J Immunol. 2011;187(5):2310-2321.

58. Kovacsovics-Bankowski M, Rock KL. A phagosome-to-cytosol pathway for exogenous antigens presented on MHC class I molecules. Science. 1995;267(5195):243-246. 
59. Moon JJ, Suh H, Bershteyn A, et al. Interbilayer-crosslinked multilamellar vesicles as synthetic vaccines for potent humoral and cellular immune responses. Nat Mater. 2011;10(3):243-251.

60. Reddy ST, van der Vlies AJ, Simeoni E, et al. Exploiting lymphatic transport and complement activation in nanoparticle vaccines. Nat Biotechnol. 2007;25(10):1159-1164.

61. Heit A, Schmitz F, Haas T, Busch DH, Wagner H. Antigen co-encapsulated with adjuvants efficiently drive protective $\mathrm{T}$ cell immunity. Eur J Immunol. 2007;37(8):2063-2074.

62. Smith DM, Simon JK, Baker JR Jr. Applications of nanotechnology for immunology. Nat Rev Immunol. 2013;13(8):592-605.

63. Schliehe C, Redaelli C, Engelhardt S, et al. CD8- dendritic cells and macrophages cross-present poly(D,L-lactate-co-glycolate) acid microsphere-encapsulated antigen in vivo. J Immunol. 2011;187(5): 2112-2121.

64. Eldridge JH, Staas JK, Meulbroek JA, Tice TR, Gilley RM. Biodegradable and biocompatible poly(DL-lactide-co-glycolide) microspheres as an adjuvant for staphylococcal enterotoxin B toxoid which enhances the level of toxin-neutralizing antibodies. Infect Immun. 1991;59(9):2978-2986.

65. Wang Y, Liang Y, Han J, et al. Attenuation of porcine reproductive and respiratory syndrome virus strain MN184 using chimeric construction with vaccine sequence. Virology. 2008;371(2):418-429.

66. Brayden DJ. Oral vaccination in man using antigens in particles: current status. Eur J Pharm Sci. 2001;14(3):183-189.

67. Lavelle EC, O'Hagan DT. Delivery systems and adjuvants for oral vaccines. Expert Opin Drug Deliv. 2006;3(6):747-762.

68. O'Hagan DT, Valiante NM. Recent advances in the discovery and delivery of vaccine adjuvants. Nat Rev Drug Discov. 2003;2(9): 727-735.

69. Amorij JP, Kersten GF, Saluja V, et al. Towards tailored vaccine delivery: needs, challenges and perspectives. J Control Release. 2012;161(2): 363-376.

70. Batista L, Pijoan C, Dee S, et al. Virological and immunological responses to porcine reproductive and respiratory syndrome virus in a large population of gilts. Can J Vet Res. 2004;68(4):267-273.
71. Bautista EM, Molitor TW. IFN gamma inhibits porcine reproductive and respiratory syndrome virus replication in macrophages. Arch Virol. 1999;144(6):1191-1200.

72. Lowe JE, Husmann R, Firkins LD, Zuckermann FA, Goldberg TL. Correlation of cell-mediated immunity against porcine reproductive and respiratory syndrome virus with protection against reproductive failure in sows during outbreaks of porcine reproductive and respiratory syndrome in commercial herds. J Am Vet Med Assoc. 2005;226(10): 1707-1711.

73. Vanderheijden N, Delputte PL, Favoreel HW, et al. Involvement of sialoadhesin in entry of porcine reproductive and respiratory syndrome virus into porcine alveolar macrophages. J Virol. 2003;77(15):8207-8215.

74. Osorio FA, Galeota JA, Nelson E, et al. Passive transfer of virus-specific antibodies confers protection against reproductive failure induced by a virulent strain of porcine reproductive and respiratory syndrome virus and establishes sterilizing immunity. Virology. 2002;302(1):9-20.

75. Yang L, Frey ML, Yoon KJ, Zimmerman JJ, Platt KB. Categorization of North American porcine reproductive and respiratory syndrome viruses: epitopic profiles of the N, M, GP5 and GP3 proteins and susceptibility to neutralization. Arch Virol. 2000;145(8):1599-1619.

76. Diaz I, Darwich L, Pappaterra G, Pujols J, Mateu E. Immune responses of pigs after experimental infection with a European strain of porcine reproductive and respiratory syndrome virus. J Gen Virol. 2005; 86(Pt 7):1943-1951.

77. Takikawa N, Kobayashi S, Ide S, Yamane Y, Tanaka Y, Yamagishi H. Detection of antibodies against porcine reproductive and respiratory syndrome (PRRS) virus in swine sera by enzyme-linked immunosorbent assay. J Vet Med Sci. 1996;58(4):355-357.

78. Spellberg B, Edwards JE Jr. Type 1/type 2 immunity in infectious diseases. Clin Infect Dis. 2001;32(1):76-102.

79. Chong CS, Cao M, Wong WW, et al. Enhancement of T helper type 1 immune responses against hepatitis B virus core antigen by PLGA nanoparticle vaccine delivery. J Control Release. 2005;102(1):85-99.

80. Ma W, Chen M, Kaushal S, et al. PLGA nanoparticle-mediated delivery of tumor antigenic peptides elicits effective immune responses. Int J Nanomedicine. 2012;7:1475-1487.
International Journal of Nanomedicine

\section{Publish your work in this journal}

The International Journal of Nanomedicine is an international, peerreviewed journal focusing on the application of nanotechnology in diagnostics, therapeutics, and drug delivery systems throughout the biomedical field. This journal is indexed on PubMed Central, MedLine, CAS, SciSearch $\AA$, Current Contents ${ }^{\circledR} /$ Clinical Medicine,

\section{Dovepress}

Journal Citation Reports/Science Edition, EMBase, Scopus and the Elsevier Bibliographic databases. The manuscript management system is completely online and includes a very quick and fair peer-review system, which is all easy to use. Visit http://www.dovepress.com/ testimonials.php to read real quotes from published authors. 